\title{
LAS CORRIDAS DE GANADO EN MOLINOS: UNA PROPUESTA DE ETNOGRAFIA VISUAL SOBRE LA TRASHUMANCIA DE GANADO EN LOS VALLES CALCHAQUÍES SEPTENTRIONALES, SALTA, ARGENTINA
}

\author{
Andrés Jakel $^{1}$ \\ Laura Teves $^{2}$
}

\section{Introducción: antecedentes de trabajo en el área}

El presente trabajo está enmarcado en un proyecto de investigación antropológico y etnográfico que tiene como meta dar cuenta de:

\begin{abstract}
..."la integración de aspectos intelectuales y prácticos de las operaciones sobre el medio natural, las variadas formas de conocer y aprovechar los recursos según la experiencia de distintas generaciones transmitida a través de diversos canales y fuentes a fin de esbozar hipótesis acerca de modalidades y tendencias en las relaciones entre las comunidades del valle y su entorno natural. Por otra parte, con relación a las interacciones del hombre con su ambiente y las estrategias de subsistencia surge la importancia del estudio de los patrones de utilización del espacio y las concepciones que estos implican." (Crivos, 2010; Teves, 2014).
\end{abstract}

Desde la perspectiva que proponemos trabajar, discutiremos el dualismo ruralurbano como modo de delimitar las comunidades y su entorno. En una primera aproximación, focalizaremos en el modo en que la gente interactúa con el ambiente. De esta relación hombre-medio deriva la forma en que es utilizado y de cómo es vivido desde la experiencia de estar inmerso en él (Milton, 1997).

En definitiva, focalizaremos en los estudios que trabajan sobre el supuesto de que los vínculos o relaciones sociales y ambientales configuran patrones de manejo de los recursos acordes a los entornos analizados y que las innovaciones se presentan como parte de las estrategias domésticas para resolver problemas en situaciones críticas. Estos estudios proveen en la actualidad una alternativa para abordar los problemas vinculados a los intereses de las personas y comunidades, y plantear objetivos de las políticas públicas.

\footnotetext{
${ }^{1}$ Universidad Nacional de La Plata, Argentina.

${ }^{2}$ Universidad Nacional de La Plata, Argentina.
} 
La consideración de la dupla modo de vida/ambiente como una misma entidad cuya principal característica es la interacción entre sus dos componentes, requiere el diseño de herramientas que destaquen el aspecto relacional a nivel teórico y que orienten los estudios empíricos actuales (Teves, 2002).

Consideramos que dentro de los enfoques actuales de la antropología centrada en la problemáticas del ambiente, es de gran importancia mostrar como éste es representado y apropiado.

\section{Encuadre teórico: la antropología ambiental}

El antropólogo británico Tim Ingold se refiere a las relaciones entre el hombre y el ambiente como un constante ajuste organismo-medio en dinámica de mutualidad. Las habilidades o las competencias necesarias para desenvolverse en un entorno determinado no vienen dadas por una determinación genética o por la interiorización de representaciones, sino que su constitución está ligada a un proceso de re-sintonización permanente, que no es disociable de los contextos prácticos de actividad en los que se produce la capacitación o habilitación. Estos procesos se encuentran siempre en curso y nunca terminados.

Desde esta perspectiva, la "vida social" no implica compartir categorías o representaciones colectivas, sino la permanente y constante coordinación de ritmos de actividad. Ingold utiliza el término "ecología de la acción” para referirse a estos procesos de re-sincronización, participación y capacitación continua en los diversos cursos de actividad, que constituyen el desenvolvimiento de los sujetos en el contexto de prácticas relacionadas al entono.

Desde este punto de vista, me interesa sobre todo trabajar el concepto de paisaje (Landscape) como una construcción continua en la cual se produce un movimiento de interpenetración de los diversos agentes que intervienen. Las trayectorias sobre las cuales se desenvuelven estos vínculos, implican procesos e sincronización con el ambiente a través de la percepción y el ejercicio de la práctica que deriva en acomodaciones y procesos de re sincronización a través de los cuales se realizan las nuevas habilidades ( $k$ kills). Ingold introducirá en este sentido el concepto de "Taskscape", para dar a entender que el entorno 
se construye al mismo tiempo en que es habitado y a en el mismo proceso. "Pensar la vida como siguiendo su curso a través de senderos nos conduce a la noción de habilidad [skill]. Focalizar en la percepción del ambiente nos lleva a pensar tanto sobre la habilidad como sobre el movimiento" (Ingold, 2012: 73).

Como primera fundamentación de nuestra propuesta metodológica de tipo verbal/visual que será desarrollada más adelante y siguiendo a Tim Ingold, podemos diferenciar tres grupos de factores que hacen necesaria una aproximación al problema desde una estrategia que incluya un registro visual.

Primero: no existe ningún código de procedimientos explicito que especifique los movimientos exactos que deben ejecutarse en cualquier tipo de circunstancia determinada en las actividades que los sujetos practican en el entorno: de hecho las habilidades prácticas de este tipo parecen ser fundamentalmente resistentes a la codificación en términos de cualquier sistema formal de reglas y representaciones (Ingold, 2000).

Segundo: No es posible separar la esfera de las relaciones de un individuo con otras personas, de la esfera de su relación con el medio ambiente "no humano". Las distintas prácticas se aprenden, se sincronizan y re-sincronizan en el ejercicio de acciones que implican vínculos entre los distintos sujetos y con el medio (Ingold, 2000).

Tercero: Diversos patrones de acciones practicadas sobre el territorio implican vinculaciones sensoriales con los objetos materiales, los animales, así como entre los diferentes sujetos y el entorno tanto a nivel visual como de otros sentidos. Estas disposiciones responden a variables que no encajan en sistemas formales de representación, como el discurso lingüístico (Ingold, 2000).

El manejo de este tipo de conocimientos no formalizados es imprescindible para desenvolverse en los diferentes entornos, y es intransferible en términos verbales (Ardevol, 1998) por lo cual incluir estrategias que permitan una aproximación en este sentido, representa gran importancia para la construcción de datos analíticos que se adapten a los objetivos de investigación.

Como puede verse fácilmente desde esta perspectiva, sin una metodología que ponga en relación elementos propios de la percepción visual con otros presentes en el discurso, la presente propuesta quedaría incompleta. 


\section{Las corridas de ganado en Molinos}

Las corridas de ganado se reconocen como una actividad propia de los habitantes de las zonas rurales durante los meses de mayo o junio de cada año. Esta actividad que consiste en el arreo del ganado vacuno desde los cerros hasta las zonas de quebrada o corrales, se realiza simultáneamente en diferentes parajes del Departamento de Molinos. La corrida implica una organización entre vecinos y parientes en la que colaboran entre ellos durante un periodo de 10 días aproximadamente.

Las tareas consisten en movilizarse desde sus casas en el pueblo de Molinos o desde los diferentes parajes para colaborar en las zonas de altura. Así hombres y mujeres coordinan un cronograma de salidas y disponen todo lo relativo a la logística para la captura de animales. Los hombres salen caminando, a caballo y con camionetas camino hacia las zonas altas o de pastaje del ganado. El objetivo es correr a los animales dispersos, agruparlos y movilizarlos hacia otros sectores. La ubicación del ganado va siguiendo distintas trayectorias, en principio permanece transitoriamente en corrales donde se reúne animales de varias familias. Las mujeres y niños también intervienen en esta actividad, en general llegan caminando o con mulas hasta los sectores donde se improvisan los campamentos. Ellas llevan las provisiones y los elementos para preparar las comidas de los hombres. Los niños también participan en las corridas. Ellos colaboran en actividades menores como acarreo de agua o en la preparación de la comida. Los niños más grandes, muestras sus habilidades con el lazo y ayudan dentro de los corrales.

Las actividades de las corridas van siguiendo un patrón de captura, separación, arreo, encierro, marcada, carneada, liberación, arreo hacia zonas más bajas, encierro final. Los animales que llegan al último corral quedarán como pago del pastaje al dueño de la finca.

La marcada finaliza con un festejo donde todos los participantes comparten una carne asada y vino. Allí hombres y mujeres de zonas muy distantes y que han prestado ayuda en las corridas es invitado a comer y tomar junto con los dueños de las fincas y los vecinos de los parajes. 


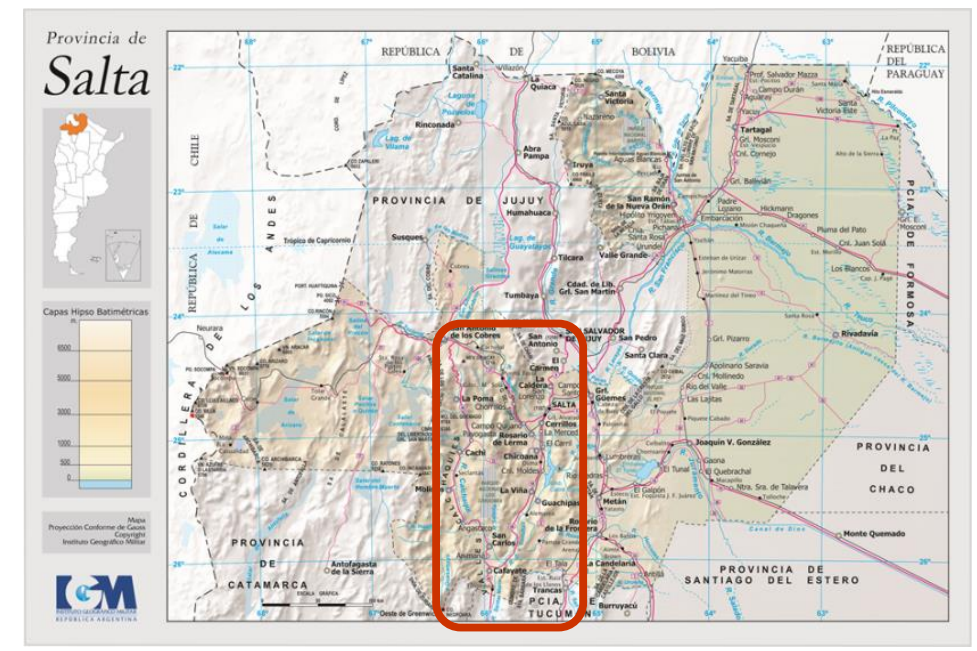

Zona de los Valles Calchaquíes Septentrionales. (IGM, 1971)

\section{El Entorno Andino y el NOA}

La región del Noroeste de Argentina -NOA- se encuentra en el extremo meridional de una región mayor que la incluye, el área de los Andes Meridionales de Sudamérica, cuyos límites pueden definirse sobre criterios no sólo geográficos, sino históricos, políticos, económicos y culturales. En este trabajo nos interesa mostrar cómo la elección de estos criterios contribuye a una delimitación y análisis particular de nuestro tema de estudio. Del que nos proponemos resulte una descripción contextualizada de las actividades de subsistencia de las comunidades locales. Para ello destacaremos los antecedentes que recuperan las raíces étnicas e históricas de la población, en la perspectiva de un modo de vida sostenido sobre la utilización de los recursos naturales disponibles en un medio ambiente particular, y en la organización económica, emplazamiento y movilidad de los grupos en el territorio de los Valles Calchaquíes. De este modo, nos proponemos caracterizar las actividades tradicionales de Molinos, tales como la agricultura, ganadería y textilería, sobre la configuración que en principio otorgan los parámetros espaciales y temporales, conjuntamente con los parámetros socioculturales. 
La influencia de diversos patrones culturales y los procesos de mestizaje en los Valles Calchaquíes tornan necesaria la consideración pormenorizada de los movimientos o flujos de poblaciones, resistencia y conflictos, así como los repoblamientos desde tiempos arqueológicos e históricos hasta la actualidad (Göbel, 1998).

Un aspecto que se suma a los anteriores, enfatiza la utilización de los recursos del medio ambiente local, la producción y autoconsumo y para la subsistencia de las poblaciones. Aproximación que permite ver el desarrollo de las actividades económicas en relación a la situación de los asentamientos humanos del Valle desde el periodo precolombino, pasando por la conquista española, las encomiendas y la conformación de los estados nacionales.

La reconstrucción de los procesos que han atravesado la vida de las poblaciones de la región desde la existencia de los grupos originarios, las influencias de otros pueblos andinos, la conquista española y el surgimiento de las poblaciones mestizas hasta el presente, señalan la existencia de visiones contrapuestas respecto a los modos de apropiación del territorio y las formas de explotación y producción de los recursos del área. (Teves, 2002).

\section{Las fincas y la producción local}

Las fincas o haciendas constituyen las denominaciones locales que los pobladores dan a las unidades de producción económica, fundamentalmente de tipo agrícolo-ganadera y que son comunes al modo de producción en otras áreas de la región del noroeste argentino.

Estas unidades dividen toda la superficie del Departamento de Molinos, limitan entre ellas y ocupan extensas superficies que recorren grandes cantidades de territorio. En algunos casos, las fincas extienden sus límites sobre diversos ambientes ecológicos propios de la zona de valles y serranías. La propiedad de estos territorios pertenece a generaciones de una misma familia de hacendados, legado que puede rastrearse a lo largo de los siglos, desde la conquista española a la actualidad. 
El modelo de trabajo de la tierra y el usufructo de la producción tiene sus orígenes en la encomienda española, y por ende algunas de sus características y relaciones actuales son las que hemos presentado en los acápites anteriores bajo la modalidad de servicio a un patrón o dueño.

Hoy, el caso de Molinos es diferente al resto de los departamentos de los Valles Calchaquíes, “donde existen un conjunto de 18 empresas agropecuarias no familiares que tienen una superficie de aproximadamente 28.000 hectáreas cada una. En promedio, las explotaciones familiares de menos de 25 hectáreas representan $80 \%$ del número total, pero cuentan sólo con 1\% de la tierra" (Popp y Gasperini, 2003: 249, 252).

Las unidades domésticas en Molinos están involucradas en la actividad económica de las fincas y por otra parte, en la agricultura y cría de ganado de altura para la subsistencia del grupo familiar. Para realizar estas actividades es indispensable la proximidad a los ríos y al manejo del agua. Las acequias o canales son construcciones que permiten el encausamiento de los cursos de agua desde las zonas de deshielo. La distribución para riego se ve favorecida por las pendientes naturales del terreno en un área que alcanza cientos de kilometros cuadros. El mantenimiento o limpieza de estos canales y la distribución de los turnos de agua de riego a los diferentes sectores, depende de una intrincada organización. El Tomero es la persona que tradicionalmente se hace responsable de esta tarea en cada población (Teves, 2011).

Durante la década de 1990 algunas de las fincas familiares fueron vendidas y adquiridas por capitales extranjeros, fundamentalmente europeos. Esta situación podría hacernos pensar sobre algunos cambios en el modo de organización e incorporación de tecnologías para la producción. Sin embargo, antes como ahora los finqueros mantienen el control de recursos en los territorios de sus propiedades, incidiendo fundamentalmente en el acceso al agua de regadío y en el control de la mano de obra local involucrada en los trabajos de producción. 
La modalidad de distribución y tenencia de la tierra en los Valles Calchaquíes afecta "la productividad y los ingresos de los pequeños productores. Como el mercado no es aquí uno de compraventa, sino, en lo fundamental, de cesión de los derechos de uso, ni el arrendatario (el pequeño productor) ni el arrendador (el propietario) invierten mayormente en los predios. En algunas localidades, por ejemplo, se pierde una parte considerable del agua del turno de riego, porque los arrendatarios usan sólo aquella necesaria para sus cultivos y no almacenan la restante, sencillamente porque no han construido embalses, dado que cualquier mejora en el predio alquilado quedaría en manos del propietario al término del contrato respectivo. Tampoco es rentable hacer esas inversiones en el caso de los medieros y aparceros, porque los contratos son de muy corto plazo." (Popp y Gasperini, 2003: 266).

La agricultura es una actividad que también se desarrolla a escala de las unidades domésticas y con la función de garantizar la subsistencia del grupo familiar, el consumo y el intercambio es la prioridad entre las familias de los sectores altos y bajos del valle.

La cría de ganado está directamente vinculada a la producción artesanal de tejidos e implica un importante incremento en los ingresos familiares, de lo cual surge un creciente interés de los tejedores por la obtención de materias primas. En este sentido se explica el por qué las familias tienen contactos permanentes en los sectores de valles y cerros. En los cerros se ubican los arriendos y los potreros de pastajes donde se practica la ganadería de cabras, ovejas y camélidos andinos, principalmente llamas. La cría se hace a escala familiar y de modo extensivo, desplazando los rebaños por extensas zonas de pastos naturales. La actividad de cría se complementa con la obtención de subproductos, tales como leche y derivados - en especial quesos y el charqui.

\section{Arriendos, mediería, pastajes y abrebajes}

Históricamente, las fincas de Molinos como grandes unidades de producción agrícola-ganadera emplazadas en amplios territorios de miles de hectáreas y diversos medio ambientes, pertenecían a un sólo propietario con su familia. Al mismo tiempo albergan a muchos grupos familiares que trabajan a su servicio. El servicio al patrón incluía tareas diferentes para los hombres y las mujeres. Ellas atendiendo los quehaceres domésticos en la Sala o casa principal de la hacienda, así como la cocina para los peones, el trabajo de lavado e hilado de lana, y el apoyo en las tareas de cosecha. Ellos como peones en el trabajo de la tierra y en la cría de animales. Cada familia que prestaba servicio para la finca 
permanecía de por vida sujeta a esta relación, inclusive adquiriendo compromisos laborales para las generaciones siguientes, la de sus hijos y nietos (Teves, 2011).

En las últimas décadas, el régimen de tenencia de la tierra ha cambiado. Los dueños de las fincas ya no residen en el lugar, sino que viven en Salta capital, quedando las tierras como su parte de su propiedad personal o como legado familiar, por sucesión indivisa a los parientes directos. En tanto, las familias de campesinos o puesteros cambiaron su relación de trabajo con los finqueros a través de acuerdos para el arriendo de la tierra, el usufructo compartido de la producción o el pago por el pastaje para la cría de animales (Popp y Gasperini, 1999: 30).

\section{Los Fuertes de Tacuil}

En el presente trabajo no perseguimos objetivos que se vinculan a la arqueología de la región, los fuertes de Tacuil aparecen referenciados con esa denominación en la historia oral y en los testimonios y entrevistas de los interlocutores en el campo alrededor del tema de las corridas que nos proponemos abordar desde un punto de vista antropológico y etnográfico.

Los estudios arqueológicos sobre los pucarás incaicos en la zona de los valles calchaquíes han sido publicados por Verónica Williams et al (2004) y Lidia Baldini (2007). Simplemente queremos mencionar que se trata de estructuras con una gran importancia en la historia oral de la región, y será desarrollado brevemente en el análisis de las imágenes desde este punto de vista y de forma muy sencilla en tanto referencia contextual.

Se espera otorgar mayor desarrollo a este tema en el futuro ya que parece atravesar problemáticas de una gran importancia visualizadas durante el trabajo de campo. 


\section{Estrategia metodológica: la etnografía visual}

Un planteo metodológico basado en el uso de imágenes supone alguna mención acerca del campo disciplinar de la antropología visual, sobre todo en lo referente a las innovaciones frente a estrategias de trabajo basadas en el análisis discursivo y la observación.

A este respecto Lisón Arcal, sostiene que la antropología posee una larga tradición

como disciplina fundamentalmente discursiva y en este sentido los aportes de la antropología visual a la producción de conocimiento antropológico implican nuevas líneas de evidencia que no se contraponen sino se complementan a otras metodologías etnográficas, esta perspectiva se encuentra siempre en espera de nuevas propuestas de aplicación (Lison Arcal, 1999).

En esta linea John Collier plantea que la producción fotográfica (visual) es ciertamente un proceso de abstracción legítimo en la observación, puesto que se erige como un apoyo mecánico a la observación en el campo. Según Colier, este ejercicio sería uno de los primeros pasos en la expresión más precisa de la evidencia que transforma circunstancias comunes en datos para su análisis en la investigación (Collier et al, 1973).

Desde nuestra perspectiva, no pretendemos realizar un aporte específico a la antropología visual, pero entendemos que una propuesta de una metodología bien fundamentada puede significar un ejemplo de aplicación de algunas de las consideraciones que se encuentran en el foco de debates de diversos campos disciplinares antropológicos en constante construcción (Bernard, 2006).

Así, consideramos que las imágenes por si mismas no consiguen capturar estos elementos sin un anclaje en las referencias discursivas de los sujetos. Por ello se propone una estrategia que vincule ambas líneas de registro, poniendo énfasis en los elementos perceptivos visuales de las prácticas y anclándolos en referencias verbales e informaciones codificadas, de manera de llevar esta información compleja a un plano analítico y operativo (Samain, 2004). 
Encontramos que la propuesta de la Etnografía visual, diseñada por G. Bateson y Margaret Mead (1962) y replicada en numerosas experiencias de investigación, nos permite aproximarnos a elementos propios de la dimensión sensorial visual de los sistemas de actividad en el entorno.

Las unidades operativas fundamentales que resultan de la aplicación de esta estrategia son las secuencias fotográficas referenciadas en parámetros claros de tiempo y espacio, remitiendo a fragmentos de secuencias de actividad específicas.

Existen tres razones por las cuales se utilizan fotografías en lugar de otras formas de registro visual o audiovisual:

a) las ventajas que constituye este medio de registro a nivel del trabajo de campo, ya que requiere menor equipamiento y logística y ayuda a construir vínculos con los interlocutores por ser un medio menos invasivo que el registro audiovisual;

b) las fotografías permiten la construcción de secuencias que muestren desarrollo de una actividad, y al mismo tiempo permiten el análisis detallado de cada toma individualmente;

c) las fotografías constituyen unidades discretas que pueden ser fácilmente referenciadas con elementos del discurso verbal. Esto es de gran importancia ya que: "la escritura indica

y define lo que la imagen es incapaz de mostrar, y la fotografía muestra lo que la escritura no puede enunciar claramente" (Samain, 2004).

Esta metodología no pretende un alcance totalizador, sino un complemento a otras líneas de evidencia que se trabajan en el área, de forma de incluir bajo la forma de unidades discretas y analíticamente operativas, la dimensión sensorial, que es una de las partes imprescindibles para el estudio de los sistemas de actividad que los sujetos practican en su entorno.

\section{La separada de ganado en Tacuil: Una etnografía visual}

Este trabajo constituye un ejercicio etnográfico acerca de un evento particular dentro la actividad colectiva a gran escala llamada "corrida". En particular se da tratamiento al evento final llamado "separada" en el cual el ganado, después de ser reunido en un corral y marcado, el ganado es separado de acuerdo a quien es su dueño, para luego ser contabilizado y registrado. 
Al terminar este evento una parte del ganado es dirigida nuevamente hacia las tierras altas, mientras otra parte es dirigida hacia el poblado donde se hacen carneadas y celebraciones. Este ganado es destinado al consumo local e intercambio a pequeña escala en la región.

El presente desarrollo constituye una primera aproximación a un escenario por demás complejo, el cual está en el eje del proyecto de investigación del autor. Dado que esta investigación se encuentra sus etapas iniciales, en este trabajo nos limitaremos a hacer un análisis descriptivo de este evento puntual, de forma de testear la metodología y avanzar en la visualización de problemáticas sobre el terreno.

Por esta razón la propuesta consiste en una recapitulación de la experiencia vivida y por lo tanto del proceso de intercambio en el cual se fueron capturando las imágenes. La intención es explicitar de qué manera se desenvolvió el proceso de creación de las mismas. De esta forma intentaré mostrar cómo las características y particularidades de este proceso fueron quedando plasmadas en las imágenes, de manera que al desandar el camino transitado aparece nuevamente explicito el vasto contenido situacional del contexto de captura.

Se incluyen descripciones e informaciones del interlocutor e informante clave, que es quien habilitó el acceso al evento de la separada.

\section{Forma de exposición del material}

El presente trabajo se conforma de una serie de imágenes fotográficas que fueron capturadas según la estrategia ya explicada, y la referencia a la descripción textual del contexto y la situación en que se hizo la toma.

Tomaré como referencia a André Alves y su libro “Os Argonautas do Mangue”. En este trabajo el autor propone reciclar una propuesta metodológica etnográfica de doble entrada: verbal y visual, basada en la construcción de secuencias fotográficas (Alves, 2004).

Otro aspecto de esta propuesta es la organización en del material fotográfico en planchas las cuales encierran una lógica secuencial y permiten por lo tanto recomponer una narrativa visual (Samain, 2004). 
Creemos que el conocimiento en antropología se caracteriza por captar datos (en este caso etnográficos), según dos grandes tipos estrategias o fuentes posibles: por un lado los datos empíricos: que son caracterizados y organizados siguiendo categorías interpretativas del campo antropológico propiamente dicho, y por otro lado las palabras que son dichas y oídas en el campo de boca de los informantes, y que substituyen a la enunciación en el fluir de las formas de vida cotidiana.

Las antropólogas brasileñas Cornelia Eckert y Ana Luiza Carvalho da Rocha (2013) llaman a esto "letra viva" y afirman que al entrar en nuestras libretas de campo, y anotaciones, se transforma en "letra muerta": es decir, en una suerte de imagen literaria del campo tomada a partir de nuestros recortes e impresiones en la experiencia etnográfica.

La descripción de esta experiencia tanto en las imágenes literarias (escritas) y técnicas (fotografías), encierra problemas de abordaje hermenéutico y fenomenológico a la hora de encarar nuestros trabajos. No todos los antropólogos quieren dar tratamiento a este tipo de problemas en sus reflexiones metodológicas, en especial cuando las mencionadas experiencias son descriptas de forma fuertemente subjetiva y enraizada en la práctica concreta de lo vivido etnográfico, y acompañadas de una serie de aspectos de orden sensible a los cuales solo a través de una inmersión en la cultura del otro podemos acceder (Rocha y Eckert, 2013).

Siguiendo estos lineamientos, el texto que se desarrolla a continuación intenta ser una narración de la experiencia etnográfica y posee por lo tanto una lógica secuencial y cronológica. En el texto de referencia tenemos un relato elaborado por el investigador y una serie de análisis en los cuales se describen muchas impresiones acerca de los diferentes aspectos de la experiencia etnográfica vivida en campo, de gran impacto emocional y atravesada de muchos estímulos sensibles y perceptivos.

Las fotografías a color refieren a secuencias narrativas, mientras que las fotografías en blanco y negro, constituyen interrupciones momentáneas del relato siguiendo fines descriptivos. Se tomaron un total de 221 fotografías referidas al evento de separada de ganado de un total de 934 fotografías tomadas en toda la jornada. De estas se seleccionaron 55 imágenes, organizadas en 14 planchas de entre 3 y 5 fotos. Las imágenes seleccionadas fueron tomadas por el Andrés Jakel y el equipo utilizado es una cámara Nikon digital modelo D3000, con un objetivo zoom 18-55mm, y una cámara Nikon digital modelo P510. 


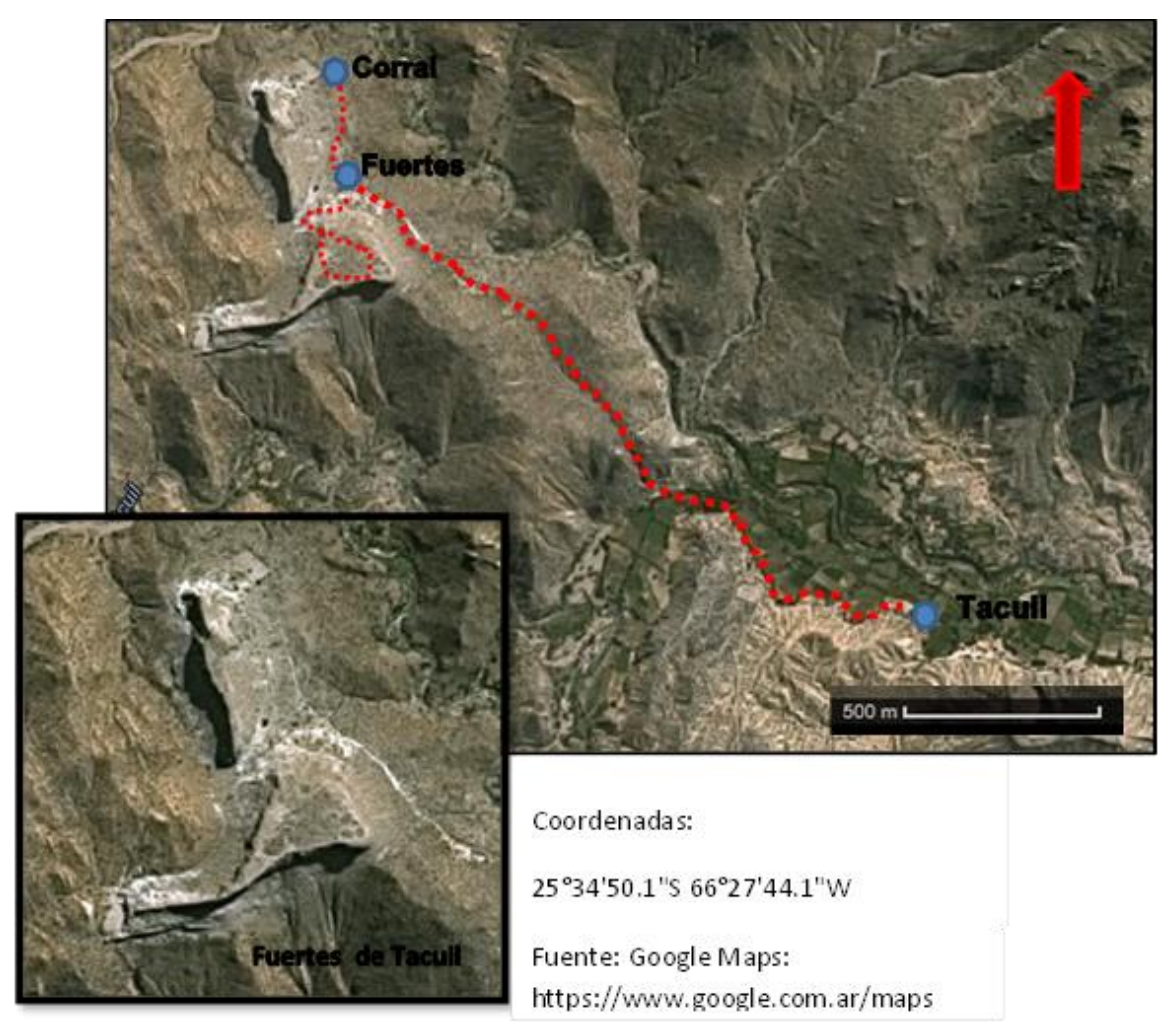

\section{Relato de la experiencia y análisis de las planchas fotográficas}

\section{9-05-2012}

Nos encontrábamos realizando una serie de tareas de campo y demás actividades en el marco de las investigaciones que el LINEA (Laboratorio de Investigación en Antropología Aplicada realiza desde hace décadas en Molinos, cuando fuimos invitados por maestros de la escuela de Tacuil, a observar la "Bajada" y "Separada" de ganado que se lleva a cabo una vez al año en esta localidad como evento final de las "Corridas" actividad de trashumancia de ganado de tipo colectiva y de gran envergadura, recurrencia y alcance regional que se desarrolla durante varios meses en los Valles Calchaquies.

La suerte quiso que estemos ahí para esa fecha y que recibamos una invitación por parte de alguien que mostrando una enorme hospitalidad y confianza pudo habilitar el acceso a este lugar. 
En esos días habíamos escuchado una historia muy renombrada y largamente referenciada en la región que es la historia del "Fuerte de Tacuil", que es el mayor monumento natural e histórico del lugar. Según los lugareños este fue el último punto de resistencia de los Calchaquies a la conquista española, un cuadro muy viejo en el almacén donde comíamos mostraba un dibujo muy claro donde se veía a los calchaquíes saltando por la cornisa antes de caer prisioneros y ser esclavizados o masacrados por los españoles. Esta historia posee mucha fuerza en el lugar y es una de las referencias históricas más fuertes.

Fue una gran alegría para nosotros dar con el hecho de que tendríamos la oportunidad de ver este lugar y fotografiarlo ya que la "Separada" se realiza, como nos explican, en un gran corral emplazado al pie del "Fuerte de Tacuil".

\section{0-05-2012}

Algunos de los miembros del equipo partimos al día 30 de Mayo hacia Tacuil con el objetivo de presenciar esta actividad al día siguiente, lo cual implico cierta preparación y logística dadas las condiciones de frio extremo y dificultad del terreno.

En el camino vimos una serie de señales que indicaban que estábamos ingresando a propiedad privada. Se nos explicó entonces que el poblado de Tacuil está emplazado dentro de una finca de producción a gran escala.

Al llegar a Tacuil se hizo un recorrido por el poblado y una cena de fraternización con el personal de la escuela que nos recibió y nos dio un lugar donde dormir, de manera que al día siguiente, dos de nosotros partiríamos a primera hora hacia el corral donde se realizaría la "Separada". El ganado ya estaba en el lugar después de varios meses de movimiento, y se estaba realizando la "Señalada", que consiste en un marcado de los animales realizado con el fin de distinguirlos de acuerdo a su propietario, según nos explicaron. 


\section{1-05-2012}

\subsection{0hs}

Dos de los miembros del equipo incluido el autor de este trabajo parten acompañados de algunos miembros del personal de la escuela hacia el lugar en el cual se realiza la separada. La temperatura es muy baja y la oscuridad es absoluta. No corre viento, el único sonido es el de nuestros pasos y nuestras respiraciones agitadas por la subida y la altura y nuestras voces. Dos linternas son la única luz para alumbrar el camino, la oscuridad es tan inmensa que parece pesar sobre nuestras espaldas. Sabemos las dimensiones del paisaje pero la oscuridad y el silencio son tan absolutos que no somos capaces de percibir la distancia más allá del alcance de nuestras linternas.

\subsection{5hs}

La primera claridad del cielo, entre azul y negro aun imposible de fotografiar con los recursos del momento, deja que se recorte contra el firmamento la imagen monumental del Pucara de Tacuil, del cual habíamos oído hablar mucho previamente. La imagen de los antiguos calchaquíes saltando al vacío aparece de inmediato, la oscuridad permite reconstruir mentalmente los escenarios e imaginar las situaciones: el pucara de Tacuil condensa pasado y presente, más de quinientos años en una sola mirada.

Casi al mismo tiempo empezamos a oír los mugidos del ganado, una experiencia diferente de todas, la voz y los quejidos de cientos de animales en encerrados en un pequeño espacio en plena oscuridad, el sonido crecía con cada nuevo paso.

\subsection{0hs}

Luego de dos horas de caminata, aun en la oscuridad, llegamos corral donde estaba pronta a realizarse la separada de ganado. Ya podíamos percibir una ínfima claridad en el cielo donde se recortaban al mirar hacia el Oeste, las dos estructuras geológicas del emblemático Fuerte de Tacuil. Lo único que se percibía a nivel del suelo era el mugido estridente de cientos de animales que un pircado de 1.5 metros, de altura separaba de nosotros, algunas luces de linternas que se movían de forma desordenada dentro del todavía presunto corral, y algunas conversaciones en vos muy baja que no se llegaban a interpretar. 
Plancha 1: primera visualización del corral. Separada
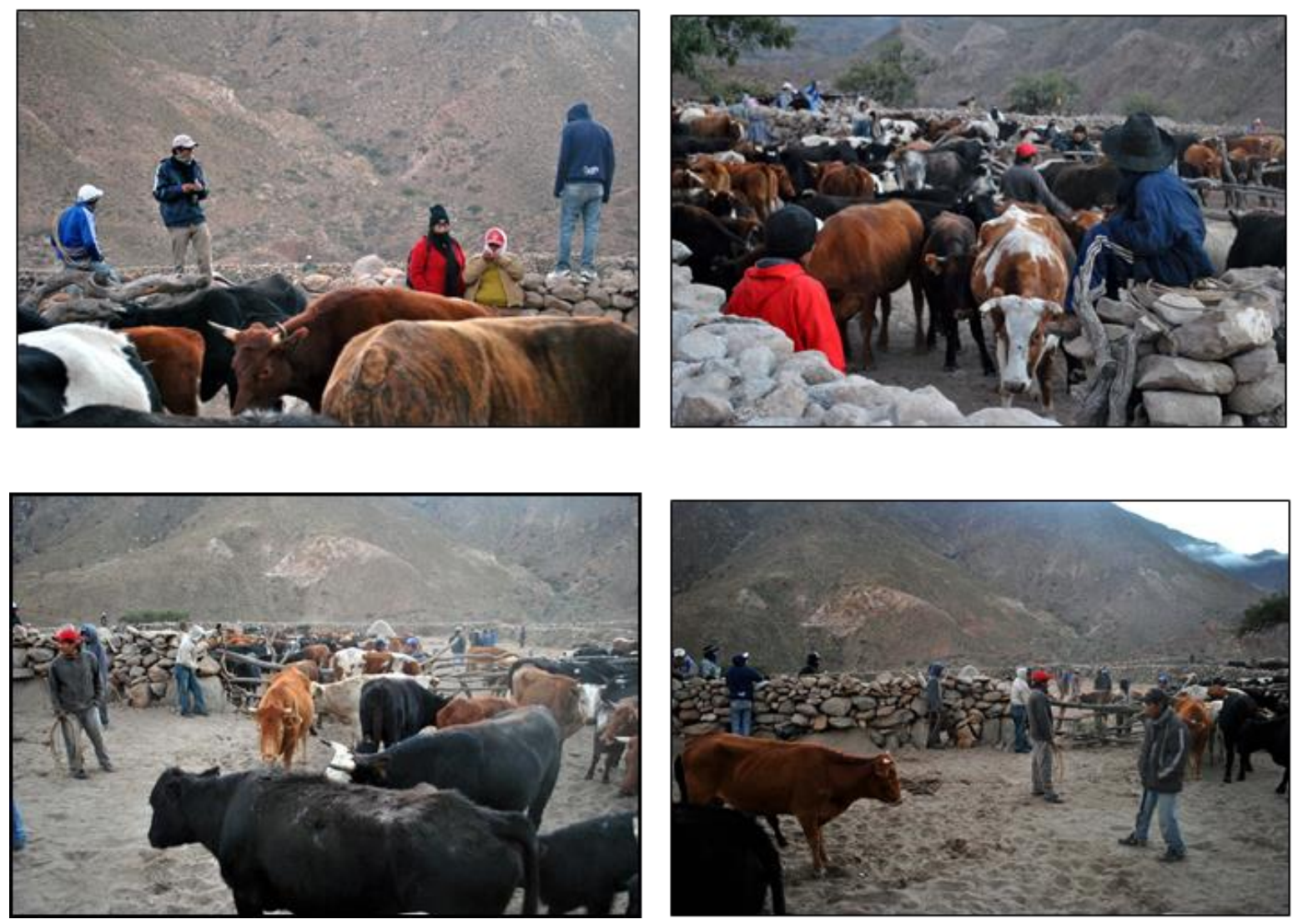


\section{Referencia: P1}

\subsection{5hs}

Comienza a aparecer la claridad del día y nos hacemos conscientes de las dimensiones de lo que estábamos presenciando: dos corrales de al menos una hectárea de superficie en total, en los cuales los hombres mantenían separado su ganado ya marcado, a la espera de su turno para que sea contabilizado e inventariado. Los animales cuentan varios cientos, según un cálculo aproximado a primera vista.

No conseguimos entender cómo mantenían el ganado separado en la oscuridad dentro de un espacio sin subdivisiones, al preguntar sobre esto la respuesta es que conocen a sus animales, posiblemente la percepción del comportamiento de los animales en el espacio excede la percepción visual por parte de estas personas con una pericia muy desarrollada en esta actividad. Es un aspecto que merece sin duda mayor indagación en el futuro.

La temperatura baja considerablemente al amanecer, al mismo tiempo que se comienzan a realizar las primeras tomas fotográficas se comienza a sentir un frio extremo.

En la foto 1 y la 2 (arriba izquierda y arriba derecha) puede observarse la distribución en personas y animales en el espacio del corral, puede apreciarse también que el pircado en tanto delimitación del adentro y el afuera es utilizado por las personas, en especial los jóvenes, que se paran sobre el para evitar ser pisado a aplastado por los pesados animales, que no atraviesan la pirca.

La mayoría de las fotos, (aunque no todas) fueron tomadas desde esta posición dado el peligro que constituye el ingreso al corral, en especial para alguien sin experiencia en el manejo de animales de gran porte.

También se puede observar el escenario que concede el entorno para esta actividad y las relaciones entre los diferentes actores que colaboran en la separada.

En las fotografías 3 y 4 (inferior izquierda e inferior derecha) se puede ver a los hombres más experimentados en el medio del espacio del corral, manteniendo dos grandes grupos de animales, para lo cual se valen de rebenques y sonidos realizados con la voz. 
A medida que los animales son contados, se los separa: una parte volverá a los cerros donde permanecerá pastando un año más, la otra parte es seleccionada para el dueño, para la venta en diferentes lugares dentro del departamento de Molinos para las carneadas festivas que acompañan a estas jornadas en el poblado de Tacuil. 
Plancha 2: regreso de ganado a zonas altas
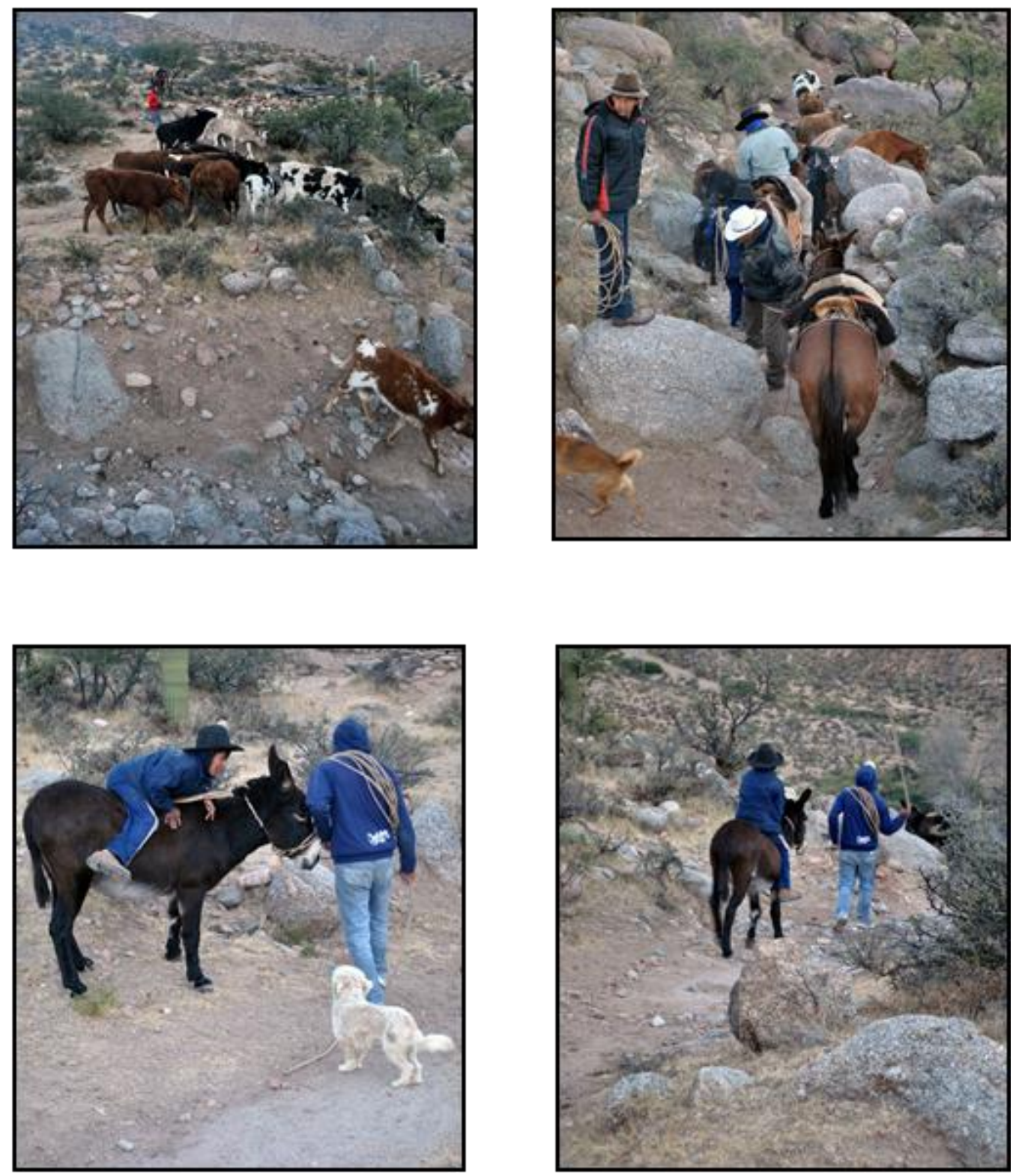


\section{Referencia: P2}

En esta plancha se observa cómo se conduce el ganado nuevamente hacia las zonas altas de los valles donde se encuentran las mejores pasturas, hacia el NO. Se hace evidente que el único fin para la bajada del ganado hasta el corral, es el conteo y el control del ganado para realizar un estudio de la reproducción y las muertes de los animales con respecto al año anterior, así también para separar lo que está listo para el consumo o para la venta.

En la primera fotografía de la plancha se observa el comportamiento del ganado sobre el terreno, los animales tienden a mantenerse juntos y seguir al grupo, pero también se adaptan a las facilidades del terreno en el caso del descenso. Lo importante es entender que estos animales toman sus decisiones y elijen por donde andar muchas veces de forma imprevisible y en contra de la intención de los arrieros. Esto puede llevar a que los animales se separen, se mezclen, e incluso que se accidenten.

En esta foto (arriba izquierda) puede verse que algunos animales se separaron del grupo y los arrieros deben precipitarse para corregir la marcha.

En las otras fotografías se observa el ganado encaminado y la pericia y la atención empleada por los arrieros para lograrlo.

En las imágenes inferiores (fotografías 3 y 4) se hace notorio el uso de animales como mulas, caballos y perros que ayudan a la tarea, y así también instrumentos como lazos y rebenques para el manejo del ganado, incluso entre los más jóvenes que aprenden desde edades muy tempranas los pormenores de esta actividad. 


\section{Plancha 3: manejo de ganado}
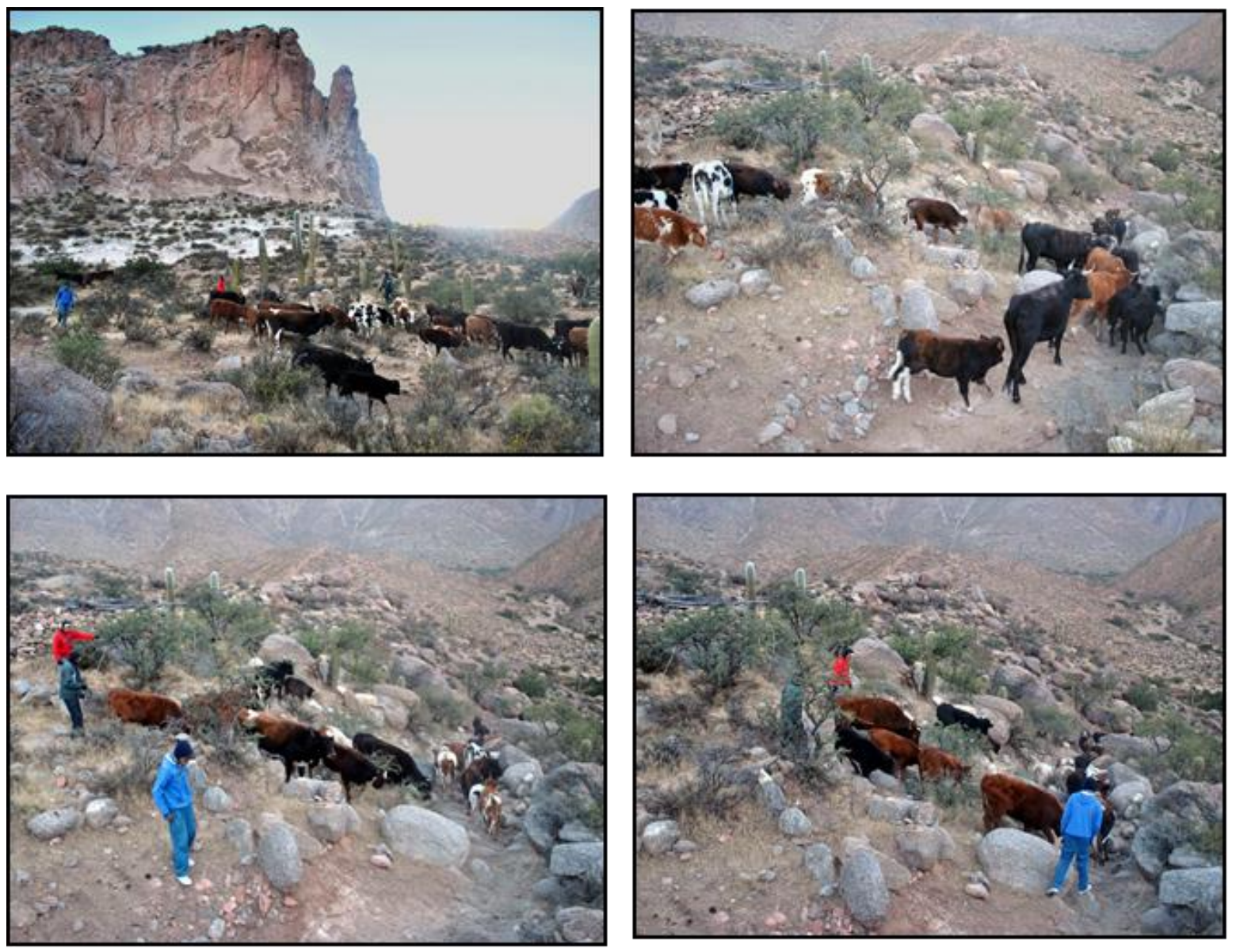


\section{Referencia: P3}

Es necesaria una gran destreza para realizar las actividades de arreo. Sobre todo, la pericia de los arrieros consiste en prever los movimientos y las decisiones de los animales, en función de su comportamiento grupal y de sus movimientos en relación a las características del territorio, es decir la presencia de obstáculos.

Esta previsión permite a los arrieros, que actúan siempre en forma grupal, visualizar cuales son los canales sobre el terreno que el ganado puede escoger y cuáles no, de esta forma puede cerrarse el paso a los animales para que no asuman las vías no deseadas por los arrieros, valiéndose de ruidos y gestos que espantan al animal en la otra dirección.

La tendencia de los animales por aprovechar los canales más sencillos para moverse, de mantenerse en grupo y de escapar a los ademanes amenazantes del arriero constituye un sistema complejo de desenvolvimiento que estas personas manejan con increíble destreza y coordinación, aun en la oscuridad y con grupos muy reducidos de gente.

Esta actividad demanda una comunicación muy fluida entre los participantes de acuerdo a códigos muchas veces gestuales que no pudimos comprender del todo hasta ahora.

En la primera imagen de esta plancha puede verse claramente el Fuerte, particularmente la cornisa desde la cual, según dicta la tradición oral, saltaron los antiguos calchaquíes al final del asedio español. Se trata de un lugar con una enorme potencia visual y simbólica, que es otro de los aspectos en torno a esta actividad que merece atención en el futuro. 
Plancha 4: conteo del ganado
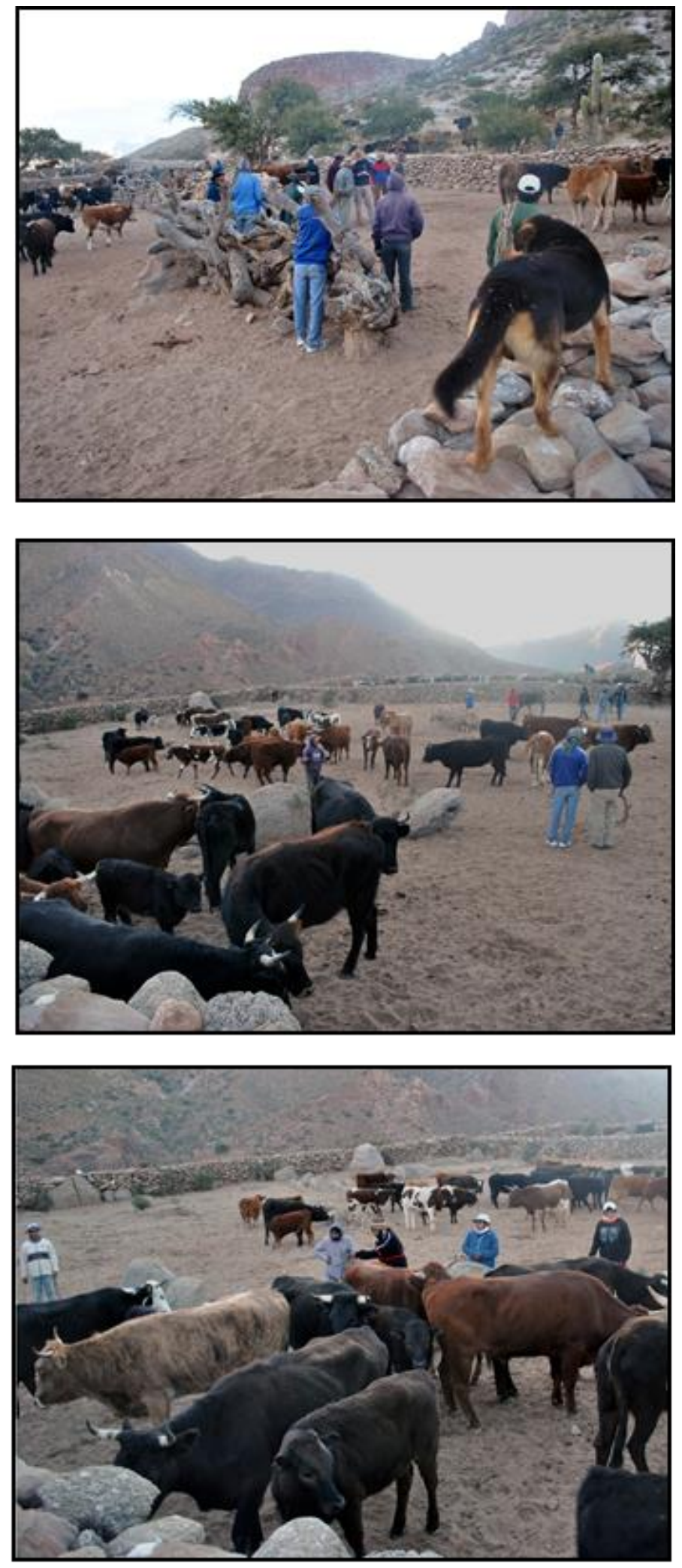


\section{Referencia: P4}

Esta es plancha más pequeña, de solo tres imágenes, colocada únicamente para señalar el conteo del ganado realizado por el finquero y los arrieros: estos mantienen el ganado separado (imágenes 2 y 3 ) hasta que sea el momento de conducirlo a un sector más pequeño del corral (imagen 1) delimitado por un tranco de árbol, donde es contabilizado y dirigido hacia fuera del corral a través de una gran tranquera que se encuentra en posición lateral.

Todos observan con gran atención el conteo y los diálogos con el propietario de las tierras (foto 1 ).

A medida que pasa el tiempo el corral queda más vacío y los animales se dirigen alternativamente hacia Tacuil o hacia las zonas altas.

En esta foto podemos observar que los perros son actores fundamentales en este proceso y que utilizan la parte superior de la pirca como canal de desplazamiento evitando así las patas del ganado. 
Plancha 5: Conteo de ganado
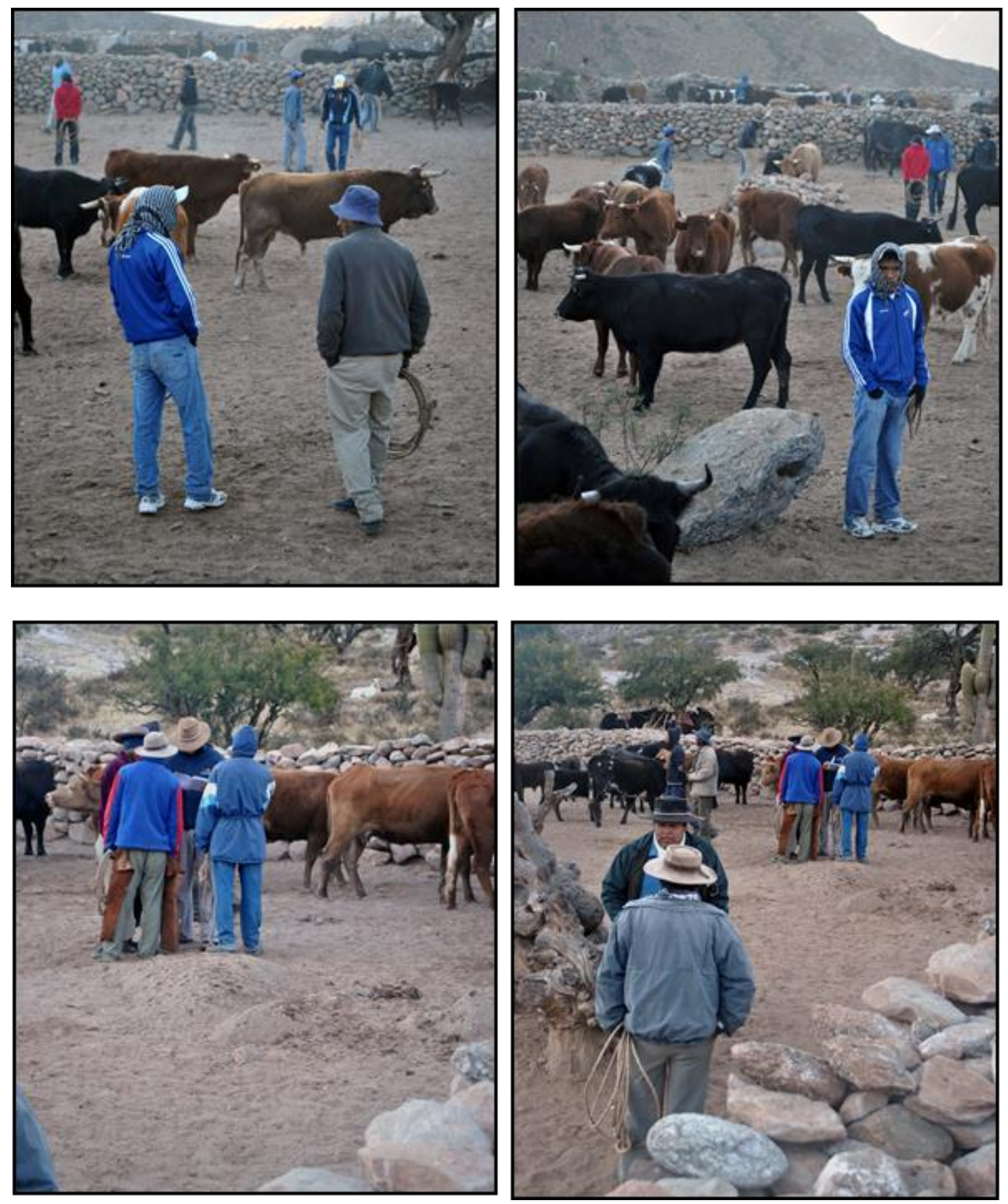


\section{Referencia: P5}

En esta plancha se observar con mayor detalle lo descripto para la plancha anterior. Se diseñó una nueva plancha con el fin de poner el acento en los diálogos e interacciones de los diferentes actores que intervienen utilizando el espacio del corral que es entonces una expresión de la complejidad de los intercambios, negociaciones y disposiciones que se llevan a cabo en este escenario.

Personas y animales son parte de este espacio de varios niveles en el cual se dirimen cuestiones que influirán las actividades y relaciones de cara al nuevo año, y al nuevo ciclo de actividad.

Muchos de estos aspectos fueron visualizados en laboratorio al realizar el análisis de las fotografías y el diseño de las planchas. Este análisis permitió rebelar algunas cuestiones que parecen nodales y que constituyen el eje de programas actuales de investigación en el lugar. 
Plancha 6a: interior / exterior del corral: espacio de frontera
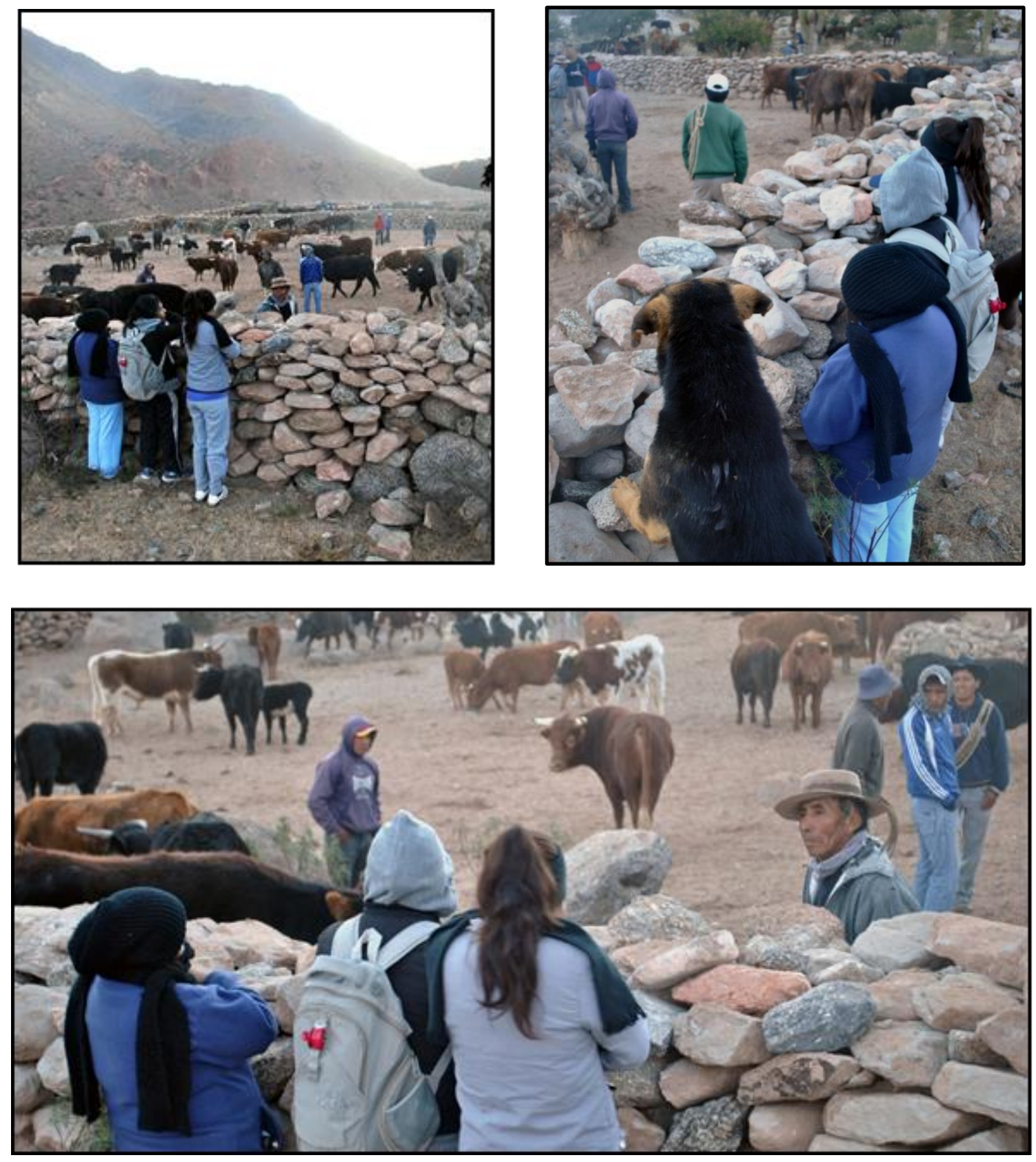


\section{Referencia: P6a}

En esta plancha se da tratamiento al espacio de frontera que conecta el interior y el exterior del corral. A primera vista, como se mencionó anteriormente, el pircado constituye un medio de delimitación entre el interior (donde está el ganado), que es un lugar de riesgo y tensión en el cual solo pueden entrar los que están encargados de las actividades de separada, ya que alguien ajeno podría entorpecer las tareas y corres un riesgo innecesario.

Este límite funciona dado el carácter de barrera física que el ganado no puede atravesar, a su vez constituye un medio de separación dada la posibilidad de arrinconar a los animales contra la pirca.

El pircado también representa un lugar de comunicación entre el interior y el exterior. En la tercera imagen (inferior) puede verse a tres maestras de la escuela que se encuentran interactuando con una persona en el interior, ambos se encuentran en situaciones muy diferentes y desde ellas estableces una conversación. Pero sobre todo se trata de un canal de comunicación visual sobre todo hacia el interior del corral donde se desarrolla la acción.

Por otra parte el pircado es una vía de traslado segura para animales y personas. La sensación de esta en el interior del corral es de una enorme tensión y riesgo, al ingresar uno debe hacerlo munido de un rebenque y prestar atención en todas direcciones, los constantes sonidos de los animales nerviosos y embravecidos da la sensación de que puede venir en cualquier momento una envestida. 


\section{Plancha 6b: refugios temporales}
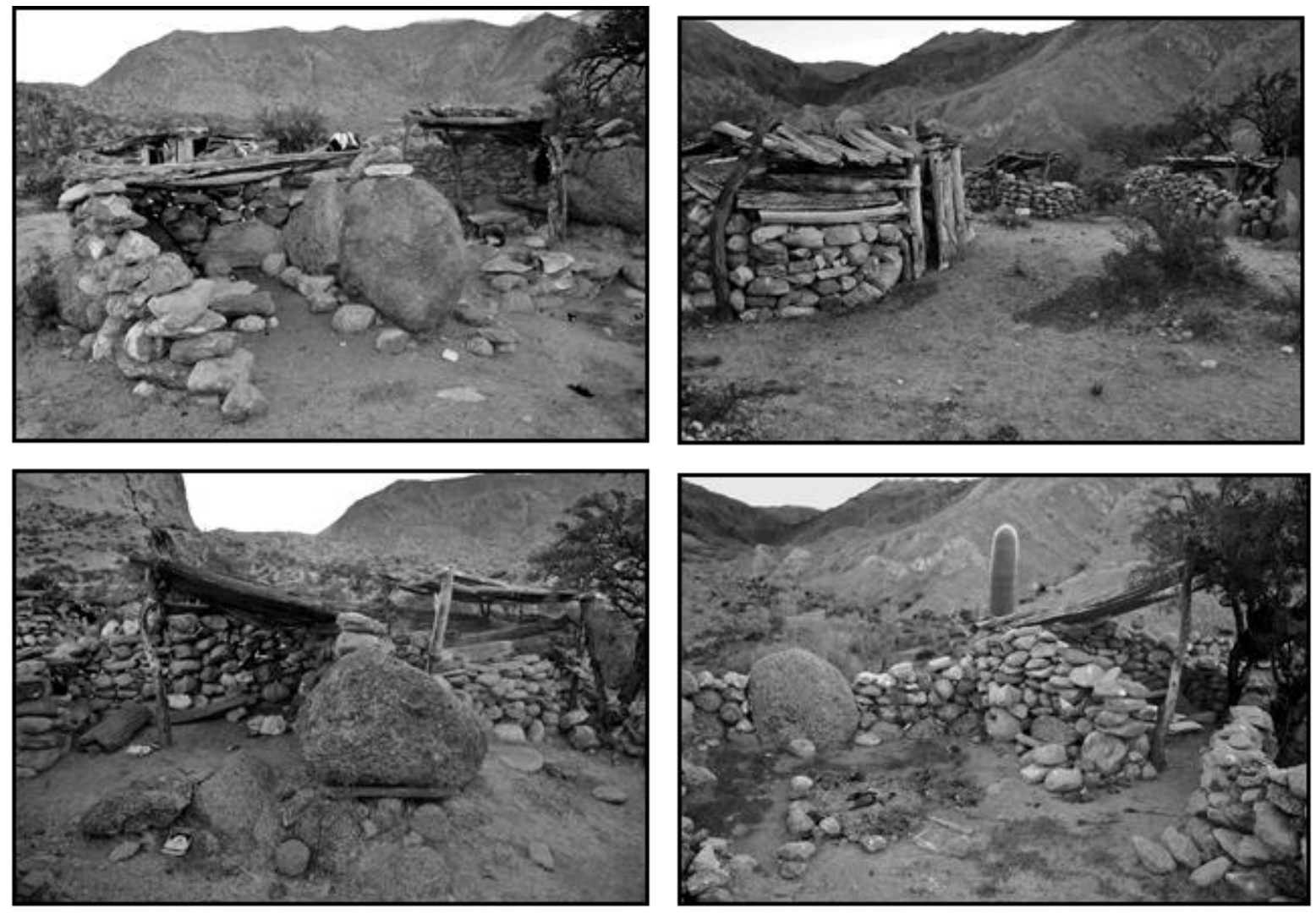


\section{Referencia: P6b}

Esta plancha anexa de carácter descriptivo, muestra los refugios temporarios construidos alrededor del corral, la mayoría al oeste del mismo. Se trata de habitaciones hechas de madera y piedra donde las personas que acompañan a la actividad se refugian durante la noche.

Según las informaciones, los distintos grupos van llegando durante varios días al lugar hasta el día de la separada, por los cual los primeros en llegar deben esperar por mucho tiempo a que el resto vaya arribando con su ganado, después de muchos días en las montañas.

Por otra parte muchos familiares vienen desde otros puntos de la provincia e incluso desde buenos aires a colaborar con los eventos finales de las Corridas, por lo tanto este es un lugar de reunión y de festejo, que marca la finalización de un largo y cansador proceso por el cual los animales son reunidos y conducidos al corral para la Separada.

Se realizan comidas comunales, se bebe vino y se celebra durante la noche.

\subsection{0hs}

Los dos miembros del equipo se separan del corral junto con uno de los miembros de la escuela como guía para realizar un recorrido por los fuertes y ascienden a uno de ellos. En el camino se observan muchos fragmentos de cerámica con señales de haber sido arrastradas por el agua durante las lluvias. 
Plancha 7: Ladera del Fuerte
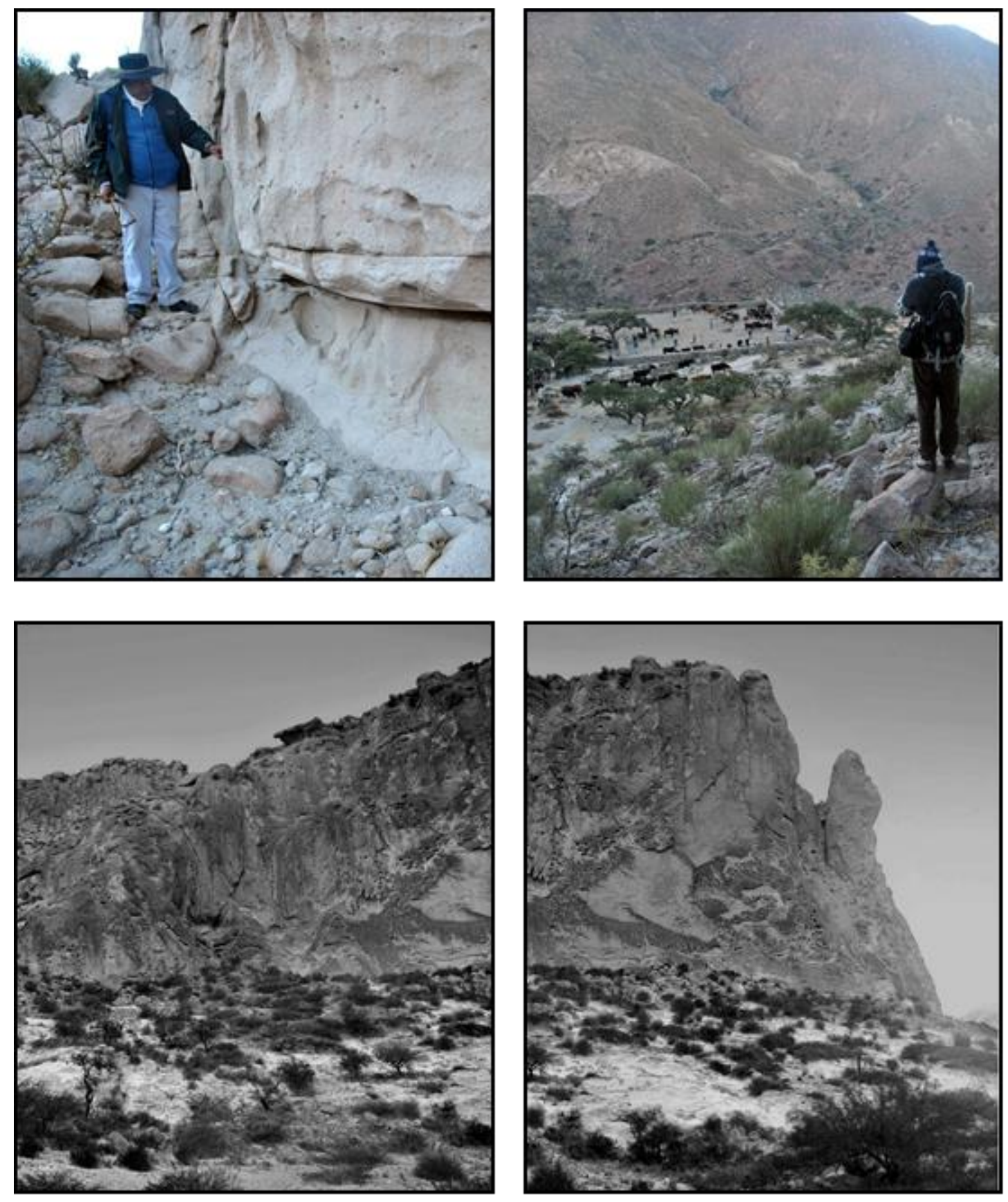


\section{Referencia: P7}

Esta plancha muestra el pie del Fuerte, en la primera imagen, nuestro guía nos muestra los resultados de la erosión sobre la roca lo cual describe muy bien su actitud orientadora dentro del recorrido.

En la segunda imagen uno de los miembros del equipo, toma una fotografía del corral de la Separada desde el punto de vista de la base del Fuerte.

Las dos fotos inferiores crean la sensación de continuidad entre los dos extremos del Fuerte, con el fin de trasmitir el poder visual de tiene sobre esta estructura en el paisaje.

La estructura está delimitada por riscos verticales de gran altura, (entre unos $100 \mathrm{y}$ unos 200 metros) y cuenta con una vasta superficie superior completamente horizontal. 


\section{Plancha 8: Ascenso al Fuerte}
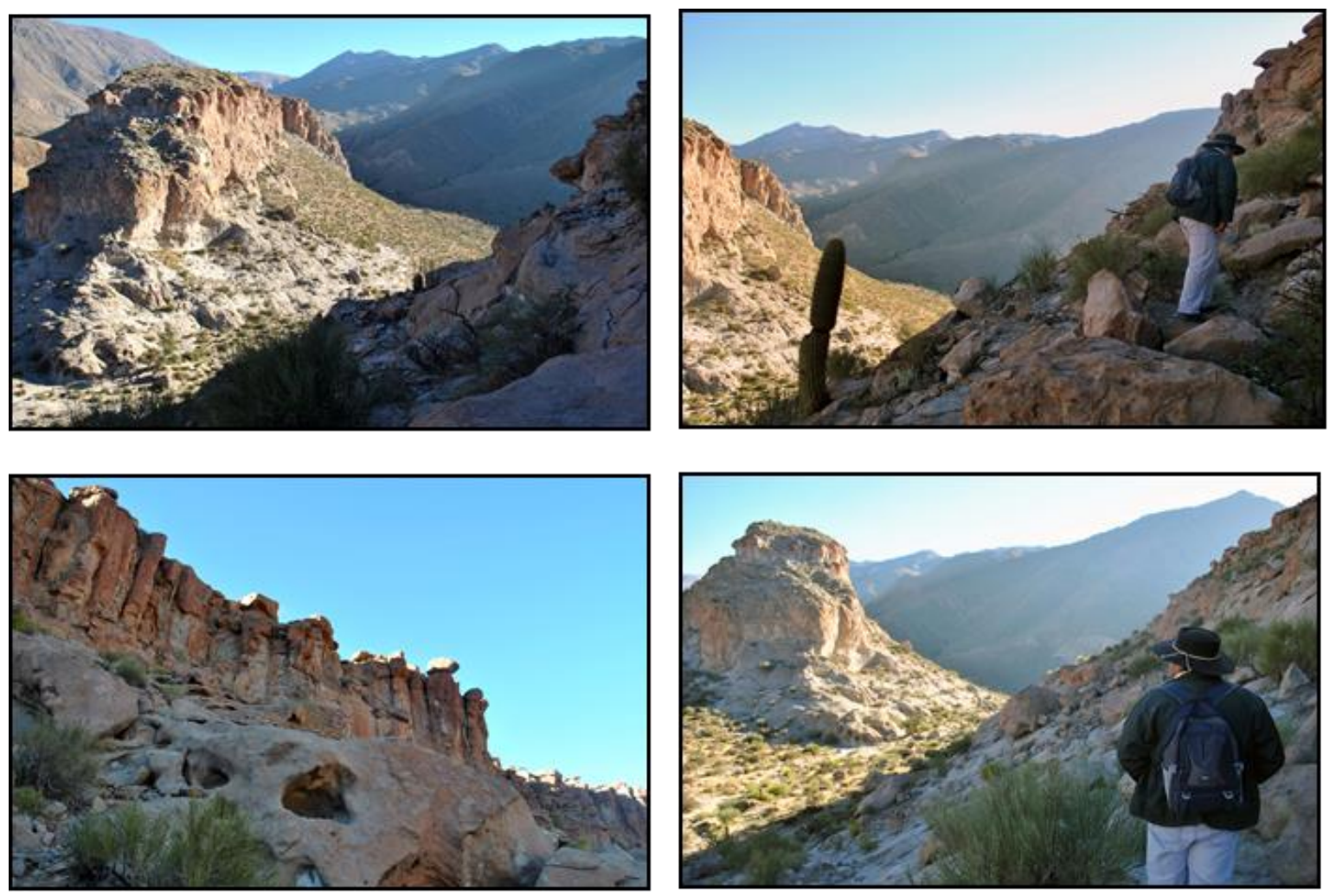


\section{Referencia: P8}

El ascenso fue muy riesgoso debido al desarrollo vertical de las laderas, y porque existen muchas piedras sueltas o trampas dejadas por los calchaquíes para los españoles en tiempos de la colonia.

La primera imagen muestra la vista desde la ladera occidental de la segunda estructura ubicada al este, a la cual el equipo ascendió. La foto fue tomada desde un punto elevado antes de alcanzar la cima.

La segunda imagen, tomada en el mismo lugar muestra a nuestro guía en pleno ascenso, nosotros seguíamos sus pasos con gran precaución procurando no caer. La tercera imagen muestra el filo de la cornisa desde abajo, también tomada en un punto elevado. El ascenso tomó alrededor de media hora. 


\section{Plancha 9a: Cima del Fuerte}
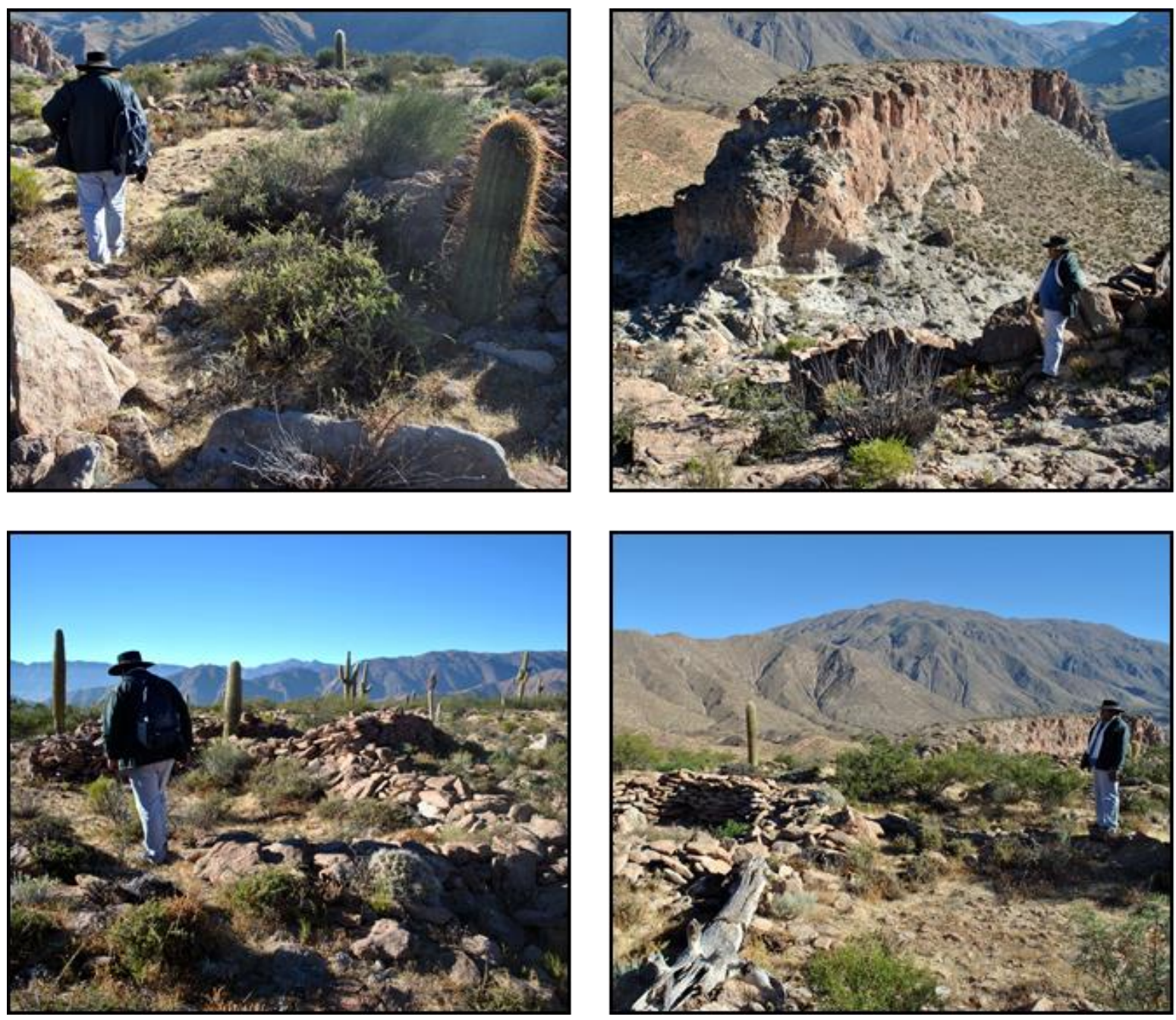


\section{Referencia: P9a}

Una vez en la cima, nos dispersamos para recorrer el lugar, con gran precaución ya que los riscos eran muy abruptos. Nos encontramos con recitos circulares de piedra con un estado de conservación increíble. Pareciera que los calchaquíes hubieran dejado el lugar muy recientemente, o que nadie hubiera estado ahí por quinientos años.

Recorrimos el lugar con enorme cuidado de no dañar la conservación del sitio. El maestro y guía en ese momento se mantuvo próximo al extremo desde el cual accedimos. Las imágenes en esta plancha muestran su comportamiento en el espacio. Él observó mucho el paisaje y no hablo muy poco mientras estábamos arriba, comprendimos que era un lugar en el que teníamos que guardar silencio y gran respeto.

Se debe aclarar nuevamente que este no pretende ser un trabajo arqueológico, ni pretende incluir descripciones de este tipo, las cuales no estamos en condiciones de efectuar, y tampoco interesan a los fines de nuestro trabajo. Solo se incluyeron estas planchas con el fin de dar contexto y transmitir la relación que se plantea entre la zona alta y baja de los fuertes, y las características de los mismos, que los lugareños conocen bien, y que sin duda participa en los fenómenos que se desarrollan aquí.

Creemos que el hecho de que el evento de la Separada, en tanto actividad culmine de la Corrida y la más conspicua se lleve a cabo en un lugar de semejante fuerza histórica, y tan visible y referenciada en la tradición oral, posee sin dudas un significado muy importante. Llama la atención la elección del lugar y la potencia que aporta como escenario de esta importante actividad, sin embargo no estamos en condiciones de arriesgar hipótesis a este respecto todavía, solo nos corresponde mencionarlo y describirlo brevemente en tanto parte de la experiencia vivida. 
Plancha 9b: estructuras arqueológicas en la cima del Fuerte
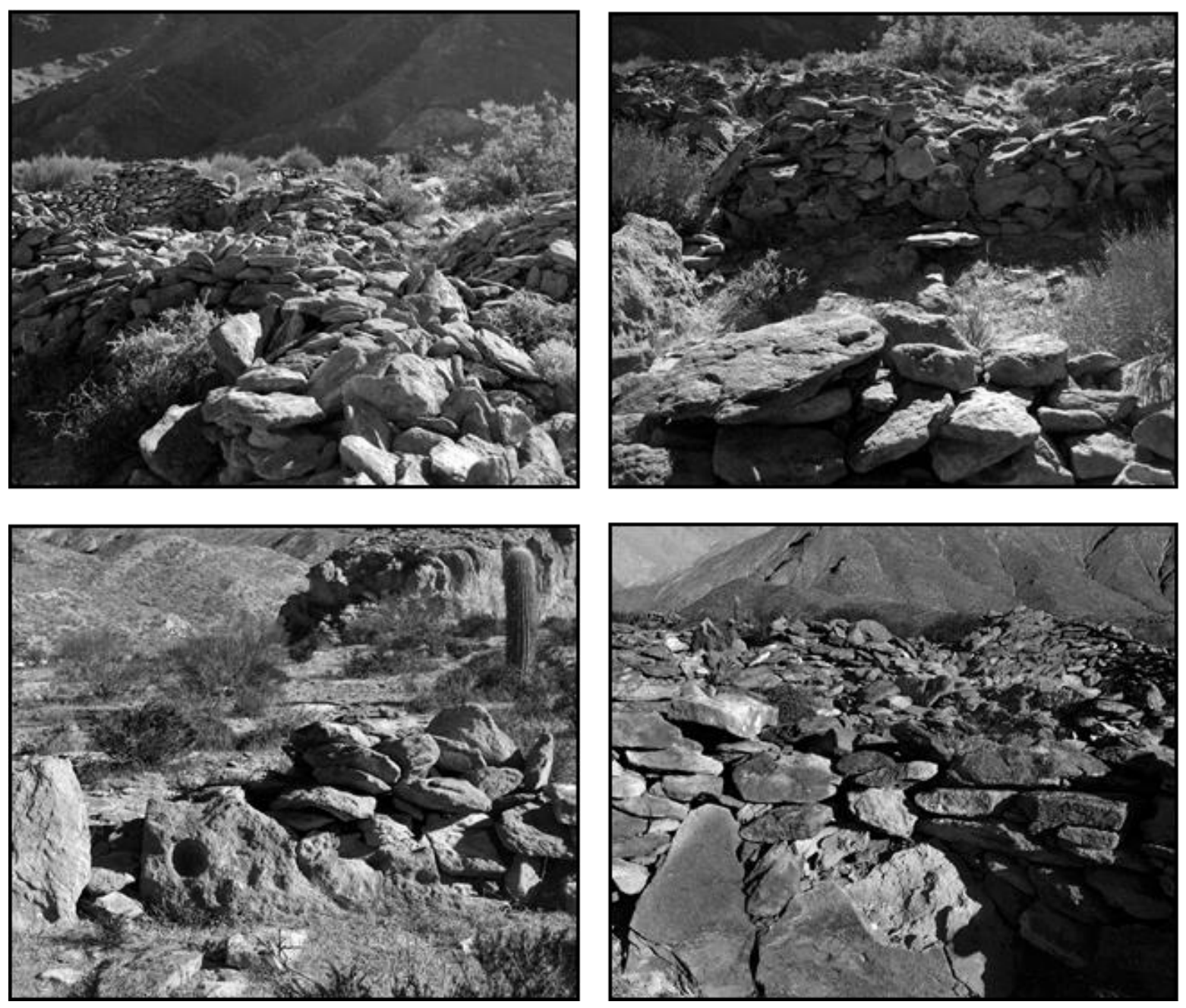


\section{Referencia: P9b}

En la cima de los fuertes, innumerables recintos de pirca intactos remanentes de la ocupación Calchaquí, muestran un estado de conservación único, según nos informan, no se han efectuado reconstrucciones.

Las imágenes superiores muestran los pircados de los recintos de habitación de forma circular sobre los cuales se construían las chozas de madera y cueros. 
Plancha 9c: estructuras arqueológicas en la cima del Fuerte
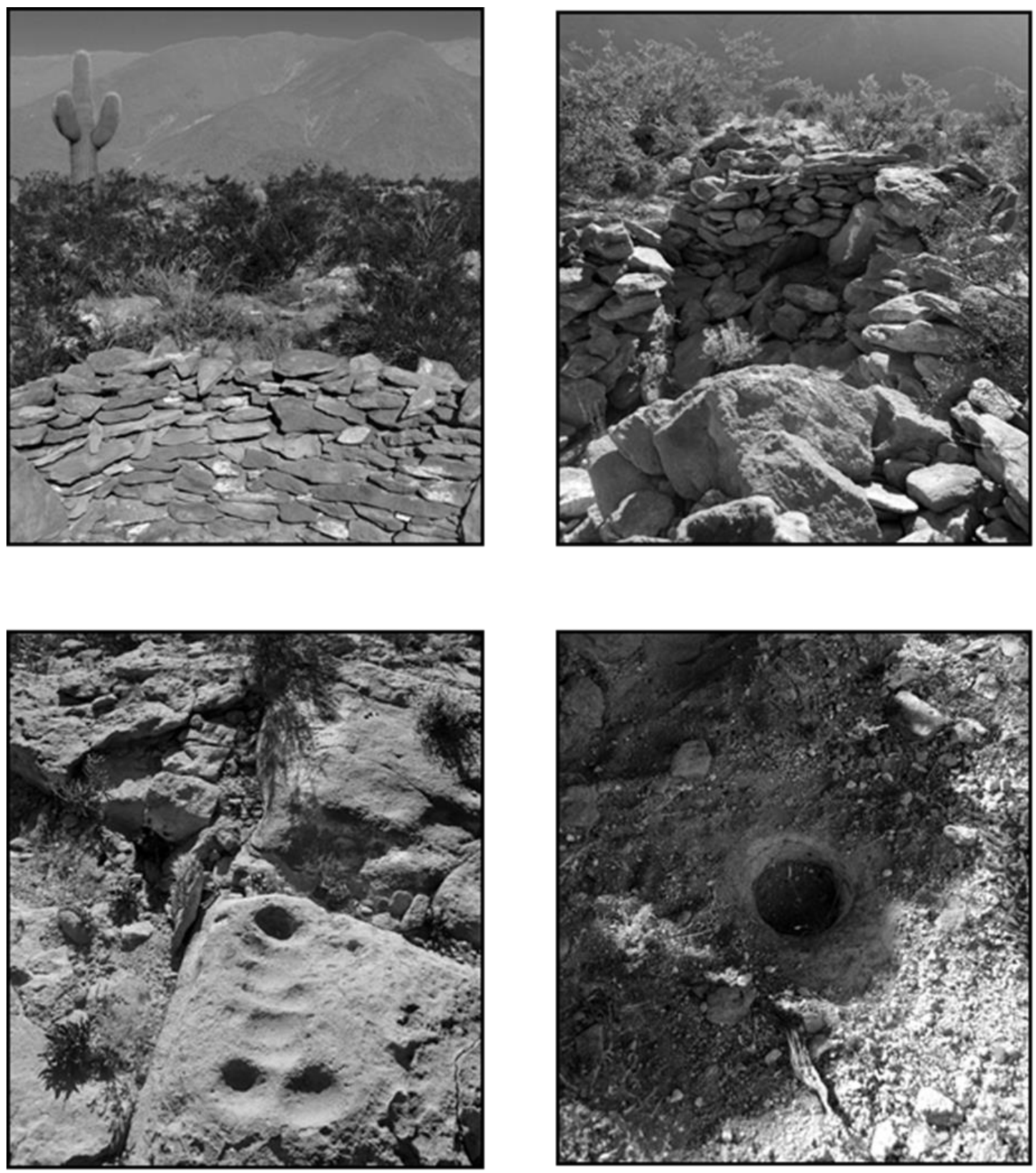


\section{Referencia: P9c}

En el centro de los recintos se observan morteros y molinos en casi todos los recintos y presencia de material cerámico fragmentado disperso en la superficie del suelo.

Pudimos ver fácilmente que el lugar podría haber albergado cientos de familias en el pasado. 
Plancha 10: regreso a Tacuil
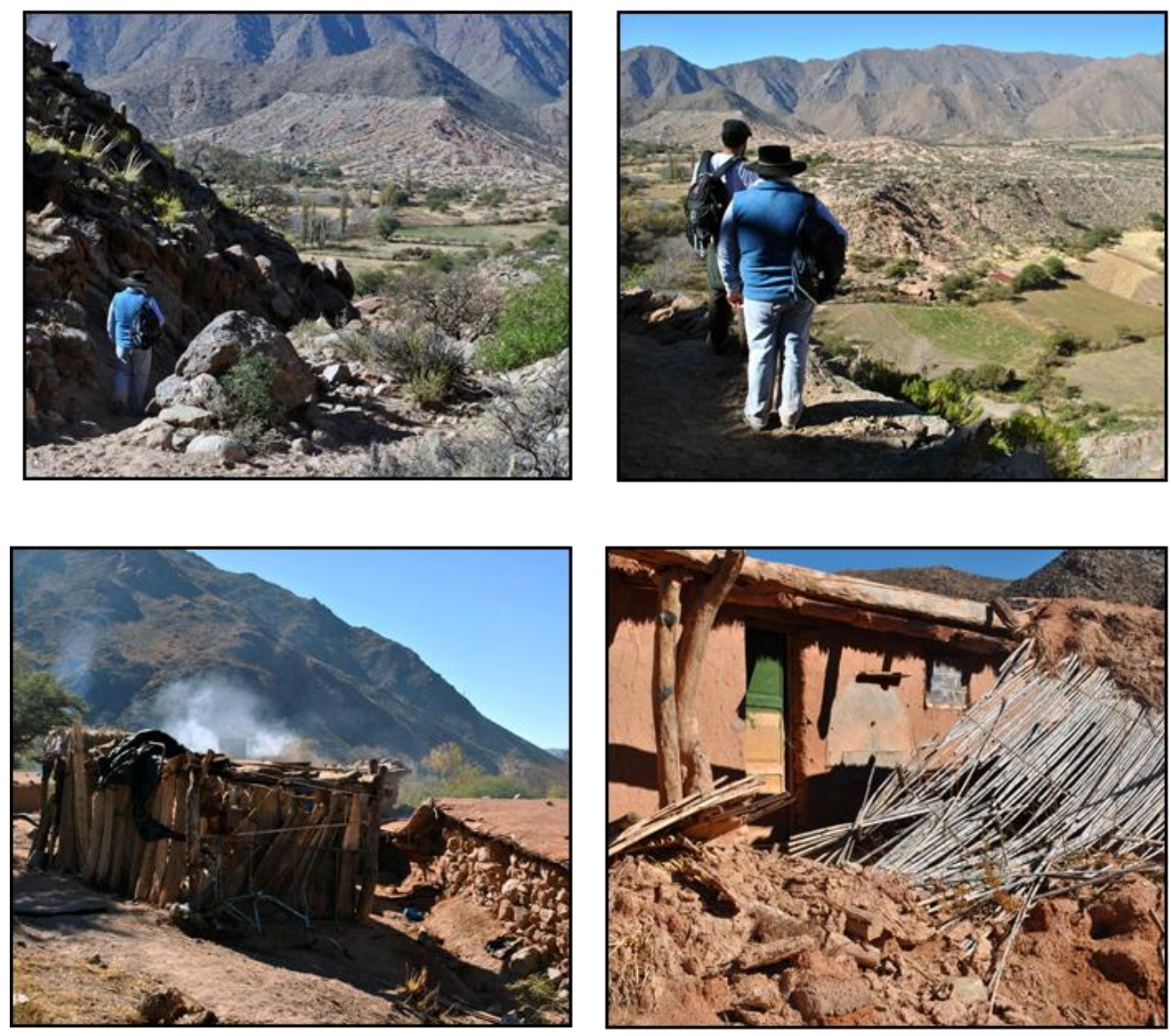


\section{Referencia: P10}

\subsection{0hs}

Los tres iniciamos el regreso, ya no hay ganado en el camino, ya había sido bajado mientras se hizo el recorrió del fuerte. El camino en pleno sol fue muy diferente de recorrer que durante la madrugada: podíamos observar el increíble paisaje hasta una gran lejanía y apreciar los riscos de gran altura que rodeaban el sendero de la bajada.

La temperatura había subido considerablemente, nos asombró mucho observar los lugares que recorrimos inconscientemente en la oscuridad unas horas antes, ya que encontramos muchos precipicios y pendientes empinadas.

\subsection{5hs}

El camino de regreso fue mucho más rápido que la ida. En una hora los tres estábamos ya en el poblado, y durante el camino nos detuvimos muchas veces para tomar fotos. Al llegar, entre las primeras casas comenzamos a encontrar numerosas carneadas en los corrales situados a la vera del camino. En el aire se percibe el olor a carne asada y se pueden observar personas transitando de un lugar a otro.

Las fotografías superiores muestran el paisaje durante el regreso: la llanura de inundación del Rio Tacuil y los extensos cultivos de la finca.

Las fotografías inferiores muestran las primeras casas de Tacuil, no puede verse a nadie pero de todas las casas brota el humo de los asados. 


\section{Plancha 11: Carneadas}
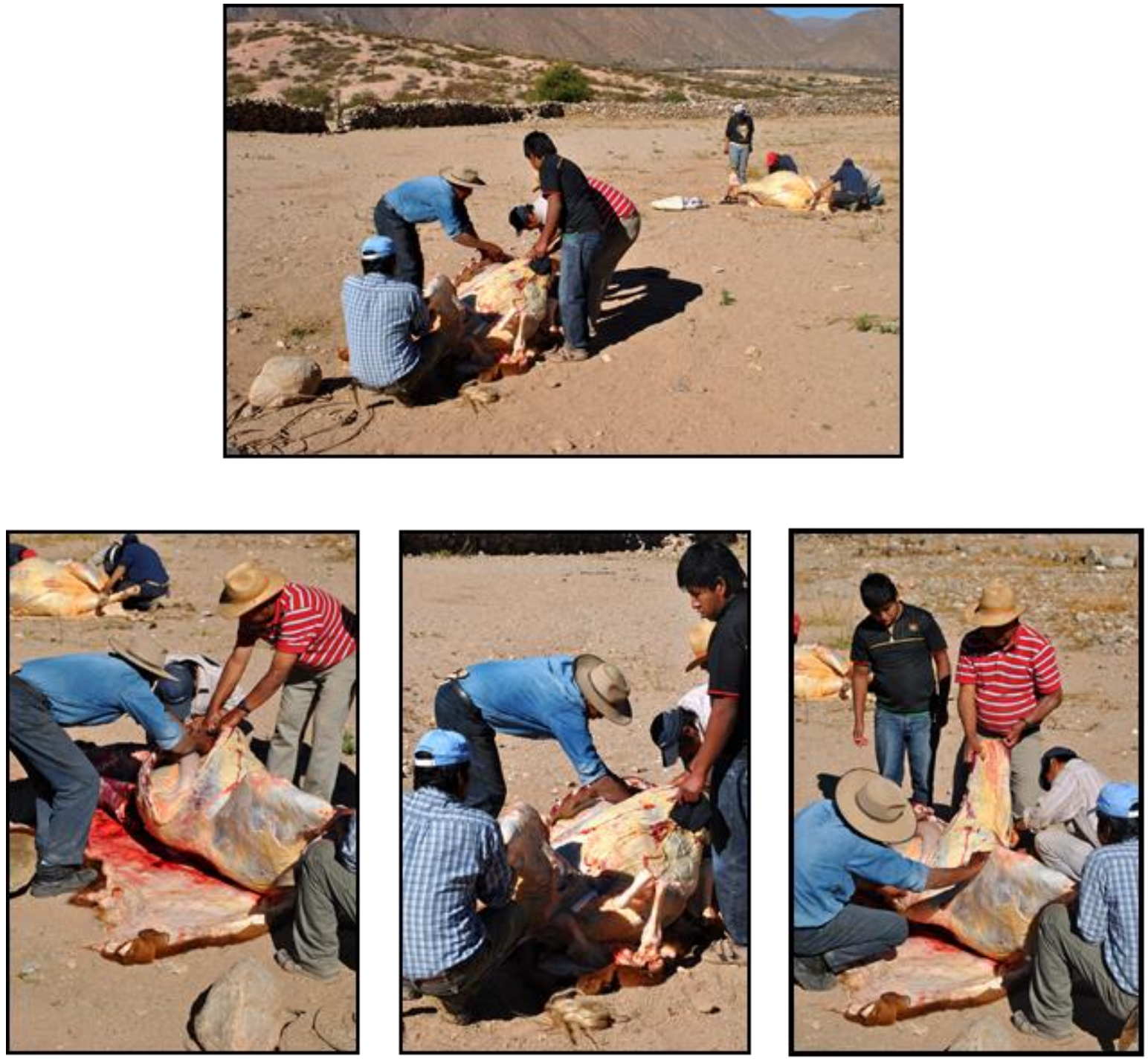


\section{Referencia: P11}

Finalmente legamos a un corral muy grande en el centro del poblado en el cual se estaban efectuando carneadas de algunos de los animales que momentos antes habían sido marcados y separados.

Las imágenes muestran la sorprendente pericia y la división de roles. En todos los casos hay un encargado de hacer los cortes e ir trozando la carne y el resto asiste la tarea.

\subsection{0hs}

Al llegar nuevamente a la escuela completamente cansados, nos recostamos en el comedor con nuestras bolsas de dormir, y dormimos hasta las 16hs, después de una jornada muy agotadora. 


\section{Consideraciones finales}

Los aspectos observados en este desarrollo poseen una gran complejidad y están atravesados por múltiples problemáticas. Su visualización fue facilitada por el uso del recurso visual / verbal bajo la forma de una metodología teóricamente fundamentada que consideramos idónea para aproximarnos la puesta en contacto de cuestiones sociales como también aquellas que están vinculadas al ambiente.

Nos propusimos aproximarnos a las relaciones hombre medio, y esta metodología nos ha permitido ver que la complejidad de la realidad viva que se desarrolla sobre el terreno de observación excede esta barrera temática, se trata de relaciones de desenvolvimiento en el cual intervienen un sin número de agentes que solo podemos estudiar desde un abordaje fenomenológico que pensamos complementario a la construcción de argumentos etnográficos rigurosos basados en el levantamiento de datos empíricos.

Esperamos en el futuro consolidar esta forma de hacer etnografía y explorar sus potencialidades a la hora de abordar las problemáticas visualizadas en esta aproximación preliminar.

\section{Agradecimientos}

Quisiéramos agradecer en primer lugar a Renzo Ríos que demostró hacia nosotros una enorme hospitalidad y confianza, y resaltar el hecho de que este trabajo hubiera resultado imposible sin sus aportes. También al Dr. Gustavo Taboada Soldati quien compartió esta experiencia inolvidable y aporto muchas de las ideas y observaciones que se utilizan en este trabajo. Por ultimo a la Dra. Rumi Kubo, quien invitó y exhortó con su interés la realización de este trabajo. 


\section{Referencias}

ALVES, André. Os argonautas do mangue precedido de Balinese character (re)visitado. Campinas: Editora Unicamp/ São Paulo: Imprensa Oficial do Estado de São Paulo, p. 240, 2004.

ARDEVOL, Elisenda. Por una antropología de la mirada. Revista de dialectología y tradiciones populares, v. 53, n. 2, p. 217-240, 1998.

BALDINI, Lidia; VILLAMAYO, Virginia. Espacios productivos en la Cuenca del Río Molinos (Valle Calchaquí, Salta). Cuadernos de la Facultad de Humanidades y Ciencias Sociales, Jujuy, Argentina, n. 32, p. 35-51, 2007.

BATESON, Gregory; MEAD, Margareth. Balinese character. A Photographic Analysis. New York: New York Academy of Sciences, 1962.

BERNARD, Russel. Research Methods in Anthropology. Qualitative and Quantitative Approaches. Lanham, New York, Toronto, Oxford: Altamira Press, 2006.

CARO FIGUEROA, Gregorio. La Patria de Güemes. Escenario de las luchas por la Emancipación. En: Atlas Total de la República Argentina. Tomo 22. Salta: Editorial Argentina, 2008.

COLIER JR, John., COUCEIRO, S. M., \& FERRAZ, I. Antropologia visual: a fotografia como método de pesquisa. São Paulo: Ed. EDUSP, 1973.

CRIVOS, Marta Alicia. Caracterización antropológica del modo de vida. Implicancias teórico-empíricas de las estrategias de investigación etnográfica. Proyecto de Investigación y Desarrollo n. 599 - Programa de Incentivos, UNLP - Año 2010-2014. 2010. GÖBEL, Barbara. Risk, Uncertainty, and Economic Exchange in a Pastoral Community of the Andean Highlands (Huancar, N.O. Argentina). En: Kinship, Networks, and Exchange. Thomas Schweizer y Douglas R. White (eds). Cambridge, UK: Cambridge University Press, p. 158-177, 1988.

INGOLD, Tim. The perception of the environment: essays on livelihood, dwelling and skill. London: Psychology Press, 2000.

INGOLD, Tim. Ambientes para la vida. Montevideo: Ediciones Trilce, p. 88, 2012.

INSTITUTO GEOGRÁFICO MILITAR (IGM). Carta Topográfica Hoja CACHI 2566 III

Provincias Fitogeográficas Dominio Chaqueño: Provincia de Monte y Prepuna. Argentina, 1971.

MILTON, Kay. Ecologías: antropología, cultura y entorno. Revista Internacional de Ciencias Sociales, v. 154, p. 86-115, 1997.

LISON ARCAL, José. Una propuesta para iniciarse en Antropología Visual. Revista de Antropología Social, n. 8, p. 15- 35, 1999.

POPP, Jurgen; GASPERINI, Maria Antonieta. El mercado de tierras en dos provincias de Argentina: La Rioja y Salta. Santiago: CEPAL, 1999.

ROCHA Ana Luiza; ECKERT, Cornelia. Etnografia da duração: Antropología das memorias coletivas em coleções etnográficas. Porto Alegre: Marcavisual, 2013.

SAMAIN, Etienne. Balinese character (re)visited. An introduction at the visual work of Gregory Bateson and Margaret Mead. En: ALVES, André. Os argonautas do mangue precedido de Balinese character (re)visitado. Campinas: Editora Unicamp/ São Paulo: Imprensa Oficial do Estado de São Paulo, p. 15-72, 2004.

TEVES, Laura. Trazas de paisajes en Molinos, un pueblo del Valle Calchaquí, Salta, Argentina. En: Denis y J. Worthington. The Power of Oral History: Memory, Healing and 
Development, Ph. Pietermaritzburg, Sudáfrica: International Oral History Association y Universidad de Natal, v. 1, p. 145, 2002.

TEVES, Laura. El Estudio Etnográfico de la Actividad Textil como aporte a la Caracterización del Modo de Vida en el Pueblo de Molinos y zona de influencia (Provincia de Salta). ARG-TPG 2453-Tesis de Postgrado. Servicio de Difusión de la Creación Intelectual (SEDiCI), UNLP, 2011. http://sedici.unlp.edu.ar/handle/10915/5239.

TEVES, Laura. Proyecto de incentivos: Análisis de Redes Sociales (ARS) como instrumento para el estudio de las estrategias de subsistencia en comunidades locales. Código N768. Programa de Incentivos del Ministerio de Educación y UNLP. Disposición R. No 252/14. 2014. Duración: 2 años.

WILLIAMS Veronica; VILLEGAS Maria Paula; GHEGGI Maria Soledad; CHAPARRO Maria Gabriela. Hospitalidad e intercambio en los valles mesotermales del Noroeste Argentino. Boletín de arqueología Pucp, n. 9, p. 335-372, 2004.

Recebido em: 03/11/2015.

Aprovado em: 22/12/2015. 